\title{
Endoglycan plays a role in axon guidance and neuronal migration by negatively regulating cell-cell adhesion
}

Thomas Baeriswyl*, Georgia Tsapara*, Vera Niederkofler, Jeannine A. Frei, Nicole H. Wilson, Matthias Gesemann, and Esther T. Stoeckli ${ }^{1}$

Institute of Molecular Life Sciences and Neuroscience Center Zurich, University of Zurich, Winterthurerstrasse 190, 8057 Zurich, Switzerland
phone: +41446354840
e-mail: esther.stoeckli@imls.uzh.ch

${ }^{1}$ corresponding author

${ }^{*}$ T.B. and G.T. contributed equally

short title: Endoglycan in axon guidance and cell migration

Key words: $\quad$ sialomucin, commissural axons, Purkinje cells, ex ovo RNAi, floor plate, cell migration, Podocalyxin-like 2 


\section{SUMMARY}

Cell migration and axon guidance are important steps in the formation of neural circuits. Both steps depend on the interactions between cell surface receptors and molecules on cells along the pathway. In addition to cellcell adhesion, these molecular interactions provide guidance information. The fine-tuning of cell-cell adhesion is as an important aspect of cell migration, axon guidance, and synapse formation. Here, we show that Endoglycan, a sialomucin, plays a role in axon guidance and cell migration in the central nervous system. In the absence of Endoglycan, commissural axons failed to cross the midline of the spinal cord. In the developing cerebellum, a lack of Endoglycan prevented migration of Purkinje cells and resulted in a stunted growth of the cerebellar lobes. Taken together, these results support the hypothesis that Endoglycan acts as a negative regulator of cell-cell adhesion in both commissural axon guidance and Purkinje cell migration.

\section{INTRODUCTION}

Cell migration and axonal pathfinding are important aspects of neural development. Neurons are born in proliferative zones from where they migrate to their final destination. After their arrival, they send out axons that have to navigate through the tissue to find the target cells with which they establish synaptic contacts. Intuitively, it is clear that the same cues provided by the environment can be used by cells and by axons to navigate through the tissue to find their target. Although we know relatively little about guidance cues for cells compared to guidance cues for axons, both processes are dependent on proper cell-cell contacts (Gomez and Letourneau, 2014; Short et al., 2016).

One of the best-studied model systems for axon guidance are the commissural neurons located in the dorsolateral spinal cord (de Ramon et al., 2016; Stoeckli, 2017 and 2018). These neurons send out their axons toward the ventral midline under the influence of the roof plate-derived repellents BMP7 (Augsburger et al., 1999) and Draxin (Islam et al., 2008). At the same time, axons are attracted to the floor plate, their intermediate target, by Netrin (for a review on Netrin function, see Boyer and Gupton, 2018), VEGF (Ruiz de Almodóvar et al., 2011), and Shh (Yam et al., 2009 and 2012). At the floor-plate border commissural axons require the short-range guidance cues Contactin2 (aka Axonin-1) and NrCAM to enter the midline area (Stoeckli 
and Landmesser, 1995; Stoeckli et al., 1997; Fitzli et al., 2000; Pekarik et al., 2003). Slits and their receptors, the Robos, were shown to be required as negative signals involved in pushing axons out of the midline area (Long et al., 2004; Blockus and Chédotal, 2016). Members of the Semaphorin family are also involved in midline crossing as negative signals mediated by Neuropilin-2 (Zou et al., 2000; Parra and Zou, 2010; Nawabi et al., 2010; Charoy et al., 2012) or as receptors for floor-plate derived PlexinA2 (Andermatt et al., 2014a). Once commissural axons exit the floor-plate area, they turn rostrally along the longitudinal axis of the spinal cord. Morphogens of the Wnt family (Lyuksyutova et al., 2003; Domanitskaya et al., 2010; Avilés and Stoeckli, 2016) and Shh (Bourikas et al., 2005; Wilson and Stoeckli, 2013) were identified as guidance cues directing postcrossing commissural axons rostrally. In the same screen that resulted in the discovery of Shh as a repellent for post-crossing commissural axons (Bourikas et al., 2005), we found another candidate that interfered with the rostral turn of post-crossing commissural axons. This candidate gene was identified as Endoglycan.

Endoglycan is a member of the CD34 family of sialomucins (Nielsen and McNagny, 2008; Sassetti et al., 2000; Furness and McNagny, 2006). The family includes CD34, Podocalyxin (also known as Thrombomucin, PCLP-1, MEP21, or gp135), and Endoglycan (also known as Podocalyxin-like 2). They are single-pass transmembrane proteins with highly conserved transmembrane and cytoplasmic domains. A C-terminal PDZ recognition site is found in all three family members (Furness and McNagny, 2006; Nielsen and McNagny, 2008). The hallmark of sialomucins is their bulky extracellular domain that is negatively charged due to extensive $\mathrm{N}$ - and $\mathrm{O}$ glycosylation. Despite the fact that CD34 was identified more than 20 years ago, very little is known about its function. It has been widely used as a marker for hematopoietic stem cells and precursors. Similarly, Podocalyxin is expressed on hematopoietic stem and precursor cells. In contrast to CD34, Podocalyxin was found in podocytes of the developing kidney (Kerjaschki et al., 1984; Doyonnas et al., 2005; Furness and McNagny, 2006). In the absence of Podocalyxin, podocytes do not differentiate resulting in kidney failure and thus perinatal lethality in mice (Doyonnas et al., 2001). Podocalyxin, but not CD34, is expressed widely in the developing and mature mouse brain (Vitureira et al., 2005; Vitureira et al., 2010). Podocalyxin was shown to induce microvilli and regulate cell-cell adhesion via its binding to the $\mathrm{NHERF}\left(\mathrm{Na}^{+} / \mathrm{H}^{+}\right.$exchanger regulatory factor) family of adaptor proteins that link Podocalyxin to the actin cytoskeleton (Nielsen et al., 2007; Nielsen and McNagny, 2008; Nielsen and McNagny, 2009). Like Podocalyxin, Endoglycan is expressed in the brain and 
in the kidney. Only low levels were found in hematopoietic tissues (Sassetti et al., 2000). Nothing is known about the function of Endoglycan.

Based on its temporal and spatial expression pattern, we first analyzed the function of Endoglycan in the embryonic chicken spinal cord. In the absence of Endoglycan commissural axons failed to turn rostrally upon floor-plate exit. Often they were observed to turn already inside the floor-plate area. Furthermore, the trajectory of commissural axons in the midline area was tortuous in embryos lacking Endoglycan but straight in control embryos. Additionally, we found that Endoglycan expression in the embryonic chicken cerebellum is restricted to migrating Purkinje cells. The absence of Endoglycan resulted in the failure of Purkinje cells to migrate properly from the ventricular zone to their destination in the periphery of the cerebellum, where they normally form the typical Purkinje cell layer. This in turn resulted in a decrease in granule cell proliferation and in the stunted growth of the cerebellar folds.

Taken together, our results are consistent with a role for Endoglycan as a negative regulator of cell-cell contact and therefore modulator of molecular interactions affecting both axon guidance and cell migration.

\section{RESULTS}

\section{Endoglycan was identified as a candidate guidance cue for commissural axons}

In a subtractive hybridization screen, we identified differentially expressed floor-plate genes as candidate guidance cues directing axons from dorsolateral commissural neurons across the midline or along the longitudinal axis after midline crossing (Bourikas et al., 2005). Candidates with an expression pattern that was compatible with a role in commissural axon navigation at the midline were selected for functional analysis using in ovo RNAi (Pekarik et al., 2003; Wilson and Stoeckli, 2011). One of these candidates that interfered with the correct rostral turning of commissural axons after midline crossing turned out to be Endoglycan, a member of the CD34 family of sialomucins. 
CD34 family members share a common domain organization that consists of a mucin-like domain followed by a cysteine-containing globular domain, a membrane associated stalk region a transmembrane spanning domain and the cytoplasmic domain (Supplementary Figure 1; Sassetti et al., 2000; Furness and McNagny, 2006; Nielsen and McNagny, 2008). With the exception of the mucin-like domain at the $\mathrm{N}$-terminus, the conservation between species orthologues of CD34, Endoglycan and Podocalyxin is in the range of $80 \%$, but drops below $40 \%$ within the mucin domain. However, homologies of these paralogous proteins within the same species are generally only in the range of $40 \%$ (Supplementary Figure 1), demonstrating that, while they might share a similar overall structure, the primary amino acid sequences can be quite diverse.

Endoglycan was expressed mainly in the nervous system during development, as levels in non-neuronal tissues were much lower (Supplementary Figure 2). In the neural tube, Endoglycan was expressed ubiquitously but with higher levels in floor-plate cells at HH2O (Hamburger and Hamilton stage 20; Hamburger and Hamilton, 1951; Figure 1). By HH26, expression was still found throughout the neural tube but now higher levels were also detected in dorsal commissural neurons ( $\mathrm{dl} 1$ neurons) and motoneurons. Endoglycan expression was also maintained in the floor plate (insert in Figure 1B). For functional analysis, dsRNA was produced from the Endoglycan cDNA fragment obtained from the screen and used for in ovo electroporation of the spinal cord at HH18 (Figure 1C). The analysis of commissural axons' trajectories at HH26 by Dil tracing in "open-book“ preparations (Figure 1D) revealed either failure to turn or erroneous caudal turns along the contralateral floorplate border in embryos lacking Endoglycan in the floor plate (Figure 1F) or in one half of the spinal cord including the floor plate (Figure $1 \mathrm{G}, \mathrm{H}$ ). Furthermore, axons were turning prematurely either before midline crossing or within the floor-plate area. Detailed analysis of the axonal morphology in the floor-plate area revealed a tortuous trajectory in embryos lacking Endoglycan (Figure $1 \mathrm{H}$ ), whereas axons crossed the midline in a straight trajectory in untreated control embryos (Figure 1E) and in embryos injected and electroporated with dsRNA derived from either CD34 (not shown) or Podocalyxin (Figure 1J).

To demonstrate specificity of Endoglycan downregulation and to verify that the phenotype was not due to an off-target effect, we used three non-overlapping cDNA fragments to produce dsRNA. All fragments resulted in the same phenotypes. Downregulation of Endoglycan with dsRNA derived from the ORF resulted in $61.7 \pm 6.4 \%$ injection sites with aberrant axon guidance. The effect on axon guidance was even stronger with dsRNA derived from the $3^{\prime}$ UTR, with $82.3 \pm 5.6 \%$ of the injection sites with aberrant axon guidance. In contrast, 
aberrant axonal pathfinding was seen only at $6.7 \pm 3.4 \%$ of the injection sites in untreated control embryos. Values were $16.2 \pm 6.0$ for EGFP-expressing control embryos, $24.6 \pm 5.8 \%$ for embryos transfected with dsRNA derived from $C D 34$, and $23.3 \pm 3.9 \%$ for embryos transfected with dsRNA derived from Podocalyxin.

\section{Lack of Endoglycan affects the morphology of the floor plate}

Because the hallmark of sialomucins is their bulky, negatively charged extracellular domain with extensive glycosylation a role as regulators of cell-cell adhesion has been postulated (Vitureira et al., 2010; Takeda et al., 2000; Nielsen and McNagny, 2008 and 2009). This together with our observation that commissural axons have a "corkscrew“-like phenotype in the midline area in Endoglycan-deficient embryos prompted us to analyze the morphology of the floor plate. Sections were taken from the lumbosacral level of the spinal cord at HH26 from control-treated and experimental embryos and stained for HNF3ß/FoxA2 to label floor-plate cells, and for Contactin2 (aka Axonin-1) to label commissural axons (Figure 2). In untreated (Figure 2A-C) and control-treated embryos (Figure 2D-F), HNF3 $3 /$ FoxA2-positive cells were aligned to form the characteristic triangular shape of the floor plate. In particular, the ventral border of the floor plate, where commissural axons traverse the midline was smooth because all floor-plate cells were precisely aligned (Figure 2A,D). In contrast, floor-plate cells were no longer aligned to form a smooth ventral border in embryos lacking Endoglycan (Figure 2G,J). On the one hand, floor-plate cells were found dislocated into the commissure formed by the Contactin2-positive axons (Figure $2 \mathrm{I}, \mathrm{L}$ ). On the other hand, the floor plate appeared to have gaps in embryos lacking Endoglycan. In addition, the floor-plate width was significantly narrower in embryos lacking Endoglycan in comparison to agematched controls (Figure 2P). However, no change in Shh or Nkx2.2 expression was found in experimental compared to control embryos, indicating that cells in the ventral spinal cord were correctly specified (Supplementary Figure 3).

When embryos lacking Endoglycan were analyzed at $\mathrm{HH} 21$, that is at a time point when axons have reached but not yet crossed the floor plate, the morphology and the width of the floor plate were not different from controls (Figure 2M-O). Thus, the absence of Endoglycan does not affect cell-cell adhesion between floor-plate 
cells. Rather the altered floor-plate morphology appears to be an indirect effect of changes in axon to floorplate adhesion.

An alternative way of demonstrating the requirement for Endoglycan in both floor plate and commissural axons was by rescue experiments (Figure 3). We used dsRNA derived from the 3'-UTR and expressed the ORF of Endoglycan either under control of the Math1 promoter (expression only in dl1 neurons) or the Hoxa1 promoter for floor-plate specific expression. We used three different concentrations of plasmid for our rescue experiments and obtained a dose-dependent effect on axon guidance. Expression of high doses of Endoglycan was never able to rescue the axon guidance phenotype. However, axon guidance was not different from control embryos after transfection of dI1 neurons with a low concentration or floor-plate cells with a medium concentration of the Endoglycan ORF (Table 1). The source of Endoglycan did not matter but the amount of Endoglycan did. Thus, we concluded that Endoglycan could be a regulator of growth cone-floor plate contact without the requirement for a specific binding partner.

\section{Endoglycan is a negative regulator of cell adhesion}

The observation that downregulation of Endoglycan in floor plate cells seemed to increase the adhesion between commissural axons and floor plate cells, together with the knowledge about its molecular features, led us to hypothesize that Endoglycan might act as a negative regulator of cell-cell adhesion. To test this hypothesis we manipulated the balance of adhesion between commissural axons and the floor plate. Commissural axons cross the midline because of the positive signals provided by the interaction of floor-plate NrCAM with growth cone Contactin2 (Stoeckli and Landmesser, 1995; Stoeckli et al., 1997; Fitzli et al., 2000). In the absence of NrCAM or Contactin2, commissural axons fail to enter the floor plate and turn into the longitudinal axis prematurely along the ipsilateral floor-plate border. The positive signal derived from the Contactin2/NrCAM interaction depends on sufficient contact between growth cone and floor-plate cells. Thus, we hypothesized that the failure to detect the positive signal due to lower NrCAM levels on the floor plate cells could be counteracted by a forced increase in growth cone-floor plate contact. We reasoned that the concomitant downregulation of NrCAM and Endoglycan would rescue the NrCAM phenotype, because the 
decrease in adhesion resulting in the failure of commissural axons to enter the floor plate would be counteracted by an increase in adhesion in the absence of Endoglycan. This is indeed what we observed (Figure 4). As found previously (Stoeckli and Landmesser, 1995; Pekarik et al., 2003), axons were frequently turning prematurely along the ipsilateral floor-plate border in the absence of NrCAM (Figure 4A). In accordance with our hypothesis, ipsilateral turns were reduced to control levels when NrCAM and Endoglycan were downregulated concomitantly (Figure 4B and C).

Additional evidence for a negative effect on adhesion of Endoglycan was found in vitro. The expression of human Endoglycan in HEK cells strongly reduced adhesion of chicken motoneurons. Less than $25 \%$ of the number of motoneurons found to stick to control HEK cells were counted on HEK cells expressing human Endoglycan (Supplementary Figure 4). In a separate series of experiments, we expressed chicken Endoglycan in COS cells and compared neurite outgrowth of control and Endoglycan-overexpressing motoneurons (Figure 5). Overexpression of Endoglycan in motoneurons significantly shortened axon length no matter whether they were growing on transfected or non-transfected COS cells (Table 2). Overexpression of Endoglycan only in COS cells co-cultured with GFP-expressing control neurons did not have a negative effect on axon length. Taken together, these in vivo and in vitro experiments confirm our hypothesis that Endoglycan acts as a negative regulator of cell-cell adhesion.

\section{Endoglycan is expressed in migrating Purkinje cells and is required for their radial migration}

After having established that Endoglycan influences commissural axon guidance by regulating cell-cell contact, we wanted to analyze whether Endoglycan also plays a role in cell migration. For this, we turned to the embryonic chicken cerebellum. Endoglycan was expressed in Purkinje cells during migration (Figure 6). At HH44, after Purkinje cells have formed their characteristic single-cell layer, Endoglycan expression was no longer detectable. Expression of Endoglycan in Purkinje cells was confirmed by co-localization of the in situ signal for Endoglycan with the Purkinje cell marker Calbindin (Figure 6G-L). 
Purkinje cells are born in the ventricular zone of the cerebellar anlage (Hatten, 1999). From there they migrate radially toward the periphery to form the distinct Purkinje cell layer (Figure 7A). In control embryos at HH38 the Purkinje cell layer is still more than one cell diameter in width but is clearly detectable in the periphery of the cerebellar lobes (Figure 7B,C). Very few, if any, Purkinje cells were found in the center of the lobes. The same was true in embryos injected with the EGFP-expression plasmid only (Figure 7D-F). In contrast, Purkinje cells were still found in the center of the lobes and close to the ventricular zone in $\mathrm{HH} 38$ embryos treated with dsRNA derived from Endoglycan (Figure 7G-I). In addition, the gross morphology of the cerebellum was severely compromised, because individual lobes failed to separate. Overall the size of the cerebellum was significantly reduced (Figure 7K,L).

\section{Aberrant migration of Purkinje cells reduces granule cell proliferation}

Purkinje cells are suggested to regulate the proliferation of granule cells (Dahmane and Ruiz i Altaba, 1999; Wechsler-Reya and Scott, 1999; Wallace, 1999; Lewis et al., 2004). It was demonstrated that Shh (Sonic hedgehog) released by Purkinje cells affected proliferation of granule cells in the outer EGL (external granule cell layer). In turn, reduced proliferation of granule cells was shown to result in changes of cerebellar morphology similar to the ones we observed after downregulation of Endoglycan (Figure 7) (Lewis et al., 2004). A reduced rate of granule cell proliferation was indeed what we found in embryos after silencing Endoglycan. When we used Pax6 as a marker for granule cells, we found a thinner EGL in experimental embryos compared to control-treated and untreated embryos (Figure 8). This decrease in EGL width was due to a reduced proliferation rate of granule cells rather than apoptosis (Figure $8 \mathrm{E}-\mathrm{H}$ ). In contrast to granule cells, the proliferation rate of Purkinje cells and other cells born in the ventricular zone at HH35 did not differ between control embryos and embryos lacking Endoglycan (Figure 8I-K).

In summary, our results demonstrate a vital role for Endoglycan in commissural axon guidance at the ventral midline and Purkinje cell migration in the developing cerebellum. In both systems, the observed phenotype is consistent with the hypothesis that Endoglycan is an essential regulator of cell-cell contacts by modulating the strength of adhesion between cells. This model is supported by observations in vitro. Neuronal attachment and 
neurite length were negatively affected by the presence of an excess of Endoglycan, indicating that Endoglycan decreases adhesive strength during neural circuit assembly.

\section{DISCUSSION}

We identified Endoglycan, a member of the CD34 family of sialomucins, in a screen for axon guidance cues involved in commissural axon pathfinding at the midline of the spinal cord. In the developing chicken cerebellum. Endoglycan is expressed exclusively in Purkinje cells during their migration from the ventricular zone to their final destination between the molecular layer and the internal granule cell layer (Figure 6). In the absence of Endoglycan, Purkinje cells failed to migrate and accumulated in the center of the cerebellar folds (Figures 7). This observation suggests a role of Endoglycan as an 'anti-adhesive' molecule that is supported by the structural features of sialomucins. The function of CD34 family members has not been characterized in detail but all the results obtained so far are compatible with an anti-adhesive role (Nielsen and McNagny, 2008). One exception are reports from the lymph node cells, the so-called high endothelial venules (HEVs) where a very specific glycosylation patterns was implicated in the interaction of CD34 and Endoglycan with Lselectin (Furness and McNagny, 2006). However, in agreement with most published studies on the role of CD34 and Podocalyxin (for reviews see Furness and McNagny, 2006; Nielsen and McNagny, 2008 and 2009) and in accordance with our observation we favor the model that suggests an anti-adhesive function of Endoglycan. This model is supported by results from in vivo and in vitro experiments that confirm a negative effect of Endoglycan on cell-cell adhesion (Figure 9).

The anti-adhesive effect of Endoglycan is mediated by the negatively charged mucin domain. Similar to the role suggested for the polysialic acid modification of NCAM, the neural cell adhesion molecule (Rutishauser, 2008; Brusés and Rutishauser, 2001; Burgess et al., 2008), Endoglycan could lower cell-cell adhesion by increasing the distance between adjacent cell membranes due to repulsion caused by the bulky, negatively charged posttranslational modifications of its extracellular domains. A similar effect was found for PSA-NCAM in hindlimb innervation (Tang et al., 1994; Landmesser et al., 1990) and in the visual system, where retinal ganglion cell axons innervating the tectum were found to regulate axon-axon adhesion versus axon-target cell adhesion (Rutishauser et al., 1988). The same mechanism was found in motoneurons, where axon-axon versus 
axon-muscle fiber adhesion was a determining factor for the appropriate innervation pattern. In contrast to PSA-NCAM that continues to play a role in synaptic plasticity in the adult nervous system, the function of Endoglycan appears to be restricted to development. Expression of Endoglycan ceased in the cerebellum after the mature wiring pattern was achieved.

At first sight, the effect of Endoglycan on floor-plate morphology appears to suggest a positive regulation of cell-cell adhesion. Floor-plate cells are precisely aligned in control embryos but are protruding into the commissure in the absence of Endoglycan. Therefore, one might conclude that in the absence of Endoglycan cell-cell adhesion between floor-plate cells is compromised, resulting in the observed structural changes. However, this scenario can be ruled out based on the analysis of younger embryos. At $\mathrm{HH} 21$ the floor plate was intact in the absence of Endoglycan, indicating that Endoglycan is not required for adhesion between floorplate cells. The morphology of the floor plate is only compromised once axons have crossed the midline. Contacts between commissural axons and floor-plate cells have to be broken when later crossing commissural axons arrive and cross (Yaginuma et al., 1991). Commissural axons crossing the floor plate are suggested to do so by close interaction with short filopodial processes of floor-plate cells. Thus, the aberrant morphology of the floor plate at $\mathrm{HH} 26$ is explained by the inability of axons to break contacts with floor-plate cells in the absence of Endoglycan, consistent with our hypothesis that Endoglycan is a negative regulator of adhesion.

Thus, the function of Endoglycan in commissural axon guidance and in Purkinje cell migration is to lower cell adhesion. In both cases, the absence of Endoglycan results in too much stickiness. In the cerebellum, excessive adhesion prevents the Purkinje cells from migrating to their target layer. At the midline of the spinal cord, excessive adhesion causes axons to adhere too much to floor-plate cells and prevents their displacement by follower axons. Rather than acting as a guidance cue or guidance receptor, we suggest that Endoglycan affects neural circuit formation by modulating the interaction of many different guidance cues and their surface receptors.

In summary, we propose an 'anti-adhesive' role for Endoglycan in axon guidance and neural migration that is fine-tuning the balance between adhesion and de-adhesion. Precise regulation of cell-cell contacts is required 
in both processes and is fundamental for developmental processes that depend on a high degree of plasticity and a plethora of specific molecular interactions.

\section{METHODS}

\section{Cloning of an Endoglycan}

A cDNA fragment from the coding sequence of Endoglycan (PODXL2; 1028-1546 bp) was obtained by RT-PCR using total RNA isolated from $\mathrm{HH} 40$ cerebellum. For reverse transcription $1 \mu \mathrm{g}$ total RNA was mixed with $0.3 \mu \mathrm{l}$ RNasin (Promega), $1 \mu$ dNTPs (5 mM), $1 \mu$ random nonamers, $1 \mu$ ITT (Promega), in $20 \mu$ l Superscript II buffer (Invitrogen). Reverse transcription was carried out for 1 hour at $42^{\circ} \mathrm{C}$. Two $\mu$ l of this mixture were used for PCR with $2.5 \mu \mathrm{l}$ forward primer (10 $\mu \mathrm{M}$; 5'-CAGACACGCAGACTCTTTC-3') and $2.5 \mu \mathrm{l}$ reverse primer (10 $\mu \mathrm{M}$; 5'CTAAAGATGTGTGTCTTCCTCA-3') using the Expand Long Template Template PCR System (Roche). The PCR conditions were $35 \mathrm{cycles}$ at $95^{\circ} \mathrm{C}$ for $30 \mathrm{sec}, 57^{\circ} \mathrm{C}$ for $30 \mathrm{sec}$ and $68^{\circ} \mathrm{C}$ for $3 \mathrm{~min}$. The PCR product was cut with BamHI/Bcll and cloned into pBluescript II KS. For cloning of full-length chicken Endoglycan, we used 5'ATGGTGAGAGGAGCTGCG-3' and 5'-GTGTTTGAGGAAGACACACATCTTTAG-3' as forward and reverse primers, respectively. A plasmid containing the full-length ORF of human Endoglycan was obtained from SourceBiosource.

\section{Preparation of DIG-labeled RNA probes and in situ hybridization}

For in vitro transcription $1 \mu \mathrm{g}$ of the linearized and purified plasmid encoding Endoglycan (EndoORF: 10281546pb, Endo3'UTR: 3150-3743bp and 5070-5754bp; numbers are derived from the human sequence), Podocalyxin (ChEST190L9) and CD34 (ChEST91D7) were used to prepare Dig-labeled in situ probes as described earlier (Mauti et al., 2006). The same fragments were used to prepare dsRNA (Pekarik et al., 2003; Baeriswyl et al., 2008; Andermatt and Stoeckli, 2014b).

\section{Northern Blot}

Total RNA was extracted from cerebrum, cerebellum, spinal cord, muscle, heart, lung and kidney from HH38 embryos using the RNeasy Mini Kit (Qiagen) and loaded on a denaturing formaldehyde gel (4.5 $\mu \mathrm{g}$ of total RNA 
per lane). The RNA was blotted onto a positively charged nylon membrane (Roche) overnight using 10x SSC as a transfer medium. The membranes were hybridized with $1.5 \mu \mathrm{g}$ preheated DIG-labeled RNA probes for Endoglycan and $G A P D H$ at $68^{\circ} \mathrm{C}$ overnight. The membrane was then washed twice with $2 \times S S C / 0.1 \%$ SDS for 5 minutes at room temperature and twice with $0.1 \times S S C / 0.5 \%$ SDS for 20 minutes at $68^{\circ} \mathrm{C}$. For detection, buffer 2 (2\% blocking reagent dissolved in $0.1 \mathrm{M}$ maleic acid, $0.15 \mathrm{M} \mathrm{NaCl}, \mathrm{pH} 7.5$ ) was added for 2-3 hours at room temperature. After incubation with anti-digoxigenin-AP antibody dissolved in buffer 2 (1:10,000; Roche) for 30 minutes at room temperature the membrane was washed twice in washing buffer $(0.3 \%$ Tween 20 dissolved in $0.1 \mathrm{M}$ maleic acid, $0.15 \mathrm{M} \mathrm{NaCl}, \mathrm{pH}$ 7.5) for 20 minutes. Subsequently, detection buffer $(0.1 \mathrm{M} \mathrm{Tris}-\mathrm{HCl}, 0.1 \mathrm{M}$ $\mathrm{NaCl}, \mathrm{pH}$ 9.5) was applied for 2 minutes before adding CDP-star ( $25 \mathrm{mM}$, Roche) for 5 minutes in the dark. For detection of the chemiluminescence a Kodak BioMAX XAR film was used.

\section{In vivo experiments}

Fertilized chicken eggs were obtained from a hatchery (Brüterei Stöckli, Ohmstal. All experiments were carried out in accordance with the recommendations of the national authorities of Switzerland (Animal Protecion Ordinance). The protocols and the experiments were approved by the cantonal veterinary office of the Canton Zurich. Embryos were staged according to Hamburger and Hamilton, 1951. As the chicken embryos are from an outbred line, every embryo can be considered a biological replicate. The numbers of embryos used for the different experiments are given in the Figure legends.

\section{In Ovo RNAi}

For functional studies in the spinal cord, we silenced Endoglycan with three different long dsRNAs. They were produced from bp 1028-1546 of the ORF, as well as bp 3150-3743 and bp 5070-5754 from the 3'UTR. The fact that we obtained the same phenotype with three different, non-overlapping dsRNAs derived from Endoglycan confirms the specificity of the approach and the absence of off-target effects. dsRNA was produced as detailed in Pekarik et al., 2003 and Wilson and Stoeckli, 2011. Because no antibodies recognizing chicken Endoglycan are available, we used in situ hybridization to assess the successful downregulation of the target mRNA.

For rescue experiments, the dsRNA was co-injected with 150 (low), 300 (middle), or $750 \mathrm{ng} / \mu \mathrm{l}$ (high) plasmid encoding the ORF of chicken Endoglycan. The ORF was either expressed under the control of the Math1 
promoter for dl1 neuron-specific expression, or the Hoxa1 promoter for floor-plate specific expression of Endoglycan

\section{Ex ovo RNAi}

To analyze the in vivo function of Endoglycan in the developing cerebellum ex ovo cultures of chicken embryos were prepared (Baeriswyl and Stoeckli, 2008; Andermatt and Stoeckli, 2014b). Injections and electroporations were performed at E8 (HH34). To have direct access to the embryo a small hole of 3 to $4 \mathrm{~mm}$ diameter was cut into the extraembryonic membranes above the eye. For positioning and stabilization of the head during injection and subsequent electroporation we used a hook prepared from a spatula. Approximately $1 \mu \mathrm{l}$ of the nucleic acid mixture consisting of a plasmid encoding EGFP under the control of the $\beta$-actin promoter (100

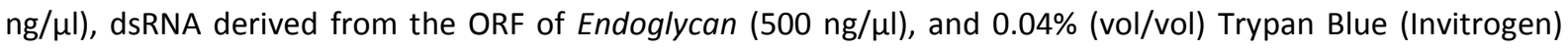
dissolved in sterile PBS were injected into the cerebellum using a borosilicate glass capillary with a tip diameter of $5 \mu \mathrm{m}$ (World Precision Instruments). Before electroporation a few drops of sterile PBS were added to the embryo. For the electroporation a platelet electrode of $7 \mathrm{~mm}$ diameter (Tweezertrodes Model \#520, BTX Instrument Division, Harvard Apparatus) was placed collaterally to the head of the embryo. Six pulses of $40 \mathrm{~V}$ and 99 ms duration were applied using a square wave electroporator (ECM830, BTX).

\section{Motoneuron adhesion assay}

Dissociated motoneurons of HH25-26 chicken embryos were cultured as described previously (Mauti et al., 2006) either on HEK293T cells stably expressing human Endoglycan-myc under the control of the CMV promoter or on untransfected HEK293T cells as control. The plasmid encoding human Endoglycan was obtained from SourceBioScience (Nottingham, UK). After $40 \mathrm{~h}$, the cultures were fixed for $1 \mathrm{~h}$ at room temperature in $4 \%$ paraformaldehyde and stained with mouse anti-neurofilament (RMO 270; Zymed) and rabbit anti-myc antibodies (Abcam). The number of neurofilament-positive cells was counted in 16 randomly selected frames $\left(0.4 \mathrm{~mm}^{2}\right)$. Similar results were obtained in 3 independent experiments. One representative example is shown in Supplementary Figure 4.

For the measurements of neurite length, motoneurons were dissected from $\mathrm{HH} 25-26$ embryos electroporated with chicken Endoglycan or EGFP as control. Dissociated motoneurons were cultured on COS cells expressing BFP (blue fluorescent protein) or BFP and chicken Endoglycan. After $24 \mathrm{~h}$, the cultures were fixed in $4 \%$ 
paraformaldehyde for $30 \mathrm{~min}$ at $4{ }^{\circ} \mathrm{C}$ and neurons were visualized with mouse anti-Neurofilament (RMO270; 1:1500) and goat anti-GFP (Rockland). The number of motoneurons per area and neurite length were quantified (Table 2). Similar results were obtained in three independent experiments. One representative example is shown in Figure 5.

\section{Tissue preparation and analysis}

To analyze commissural axon growth and guidance the embryos were sacrificed between $\mathrm{HH} 25$ and 26 . The spinal cord was removed, opened at the roof plate ('open-book' preparation) and fixed in $4 \%$ paraformaldehyde (PFA) for $40 \mathrm{~min}$ to 1 hour at room temperature. To visualize the trajectories of commissural axons, Fast-Dil (5 mg/ml, dissolved in ethanol, Molecular Probes) was injected to the dorsal part of the spinal cord as described previously (Wilson and Stoeckli, 2012). For the analysis of the cerebellum the embryos were sacrificed one to four days after electroporation. The whole brain was removed and analyzed for EGFP expression using a fluorescence stereomicroscope (Olympus SZX12). The brain tissue was fixed for two hours at room temperature in 4\% PFA in PBS. After fixation, the brain tissue was rinsed in PBS and transferred to $25 \%$ sucrose in $0.1 \mathrm{M}$ sodium phosphate buffer, $\mathrm{pH} 7.4$, for cryoprotection. In this study, $30 \mu \mathrm{m}$-thick sagittal cryostat sections were used for analysis. For the preparation of cryostat sections, the brains were embedded in O.C.T Tissue-Tek (Sakura) in Peel-a-Way ${ }^{\circledR}$ disposable embedding molds (Polysciences), frozen in isopentane on dry ice and cut on a cryocut (CM1850, Leica Microsystems). The sections were collected on SuperFrost ${ }^{\circledR}$ Plus microscope slides (Menzel-Glaeser).

\section{Immunohistochemistry}

Cryostat sections were rinsed in PBS at $37^{\circ} \mathrm{C}$ for 3 minutes followed by 3 minutes in cold water. Subsequently the sections were incubated in $20 \mathrm{mM}$ lysine in $0.1 \mathrm{M}$ sodium phosphate $(\mathrm{pH} 7.4)$ for 30 minutes at room temperature before being rinsed in PBS three times for 10 minutes. The tissue was permeabilized with $0.1 \%$ Triton in PBS for 30 minutes at room temperature and then washed again three times with PBS for 10 minutes. To prevent unspecific binding of the antibody the tissue was blocked with $10 \%$ fetal calf serum (FCS) in PBS for one hour. Rabbit anti-GFP (1:250; Abcam), anti-axonin-1 (rabbit 1:1000 or goat 1:500), anti-Calbindin D-28K (1:2000, CB38a; Swant) and mouse anti-HNF3 3 (supernatant; 4C7, DSHB) were dissolved in 10\% FCS/PBS and incubated overnight at $4^{\circ} \mathrm{C}$. After three washes in PBS, 10\% FCS in PBS was applied again for one hour, followed 
by the incubation with goat anti-rabbit IgG-Alexa488 (1:250; Molecular Probes), donkey anti-rabbit IgG-Cy3

(1:200; Jackson ImmunoResearch) or goat anti-mouse IgG-Cy3 (1:250; Jackson ImmunoResearch) diluted in $10 \%$ FCS in PBS for 90 minutes at room temperature. The tissue was rinsed 5 times in PBS for 12 minutes and then mounted in Celvol (Celanese) or Mowiol. The staining of cryostat sections was analyzed with an upright microscope equipped with fluorescence optics (Olympus BX51).

\section{Analysis of cell proliferation and cell death}

To assess cell proliferation in the developing cerebellum, we used BrdU incorporation. Embryos were injected and electroporated at $\mathrm{HH} 34$ with dsRNA derived from Endoglycan and the EGFP plasmid or with the EGFP plasmid alone. After $1(\mathrm{HH} 35)$ or 4 days (HH38) $200 \mu \mathrm{ll} 50 \mathrm{mM}$ BrdU in $\mathrm{H}_{2} \mathrm{O}$ were pipetted onto the chorioallantois. After $3 \mathrm{~h}$ the embryos were sacrificed, the brains were dissected and prepared for cryostat sections as described above. For visualization of the incorporated $\mathrm{BrdU}$, the sections were incubated in $50 \%$ formamide in $2 x S S C$ for 1 to $2 \mathrm{~h}$ at $65^{\circ} \mathrm{C}$, rinsed twice in $2 x S S C$ for 15 min followed by incubation in $2 \mathrm{~N} \mathrm{HCl} \mathrm{for}$ $30 \mathrm{~min}$ at $37^{\circ} \mathrm{C}$. Sections were rinsed in $0.1 \mathrm{M}$ borate buffer $(\mathrm{pH} 8.5)$ for $10 \mathrm{~min}$ at room temperature, followed by PBS (six changes). BrdU was detected with mouse anti-BrdU (Sigma; 1:200) using the protocol detailed above. Sections were counterstained with DAPI ( $5 \mu \mathrm{g} / \mathrm{ml}$ in PBS) for $20 \mathrm{~min}$ at room temperature. Apoptosis was analyzed as described previously (Baeriswyl and Stoeckli, 2008).

\section{Quantification}

Dil injections sites in open-book preparations were analyzed by an experimenter blind to the experimental condition, using an upright microscope equipped with fluorescence optics (Olympus BX51). All measurements including floor-plate width, thickness of the commissure, spinal cord width, Calbindin fluorescence intensities, real and outer cerebellar circumference, EGL thickness, and number of BrdU positive cells were performed with the analySIS Five software from Soft Imaging System. For all measurements, embryos injected with dsRNA derived from Endoglycan were compared with embryos injected with the EGFP plasmid only, and untreated controls. For statistical analyses ANOVA with Bonferroni correction was used except for the rescue experiments, where Tukey's multiple comparison test was used instead. Values are given as mean \pm SEM. 1 asterisk: $\mathrm{P}<0.05 .2$ asterisks: $\mathrm{P}<0.01 .3$ asterisks: $\mathrm{P}<0.001$. 
bioRxiv preprint doi: https://doi.org/10.1101/425207; this version posted September 24, 2018. The copyright holder for this preprint (which was not certified by peer review) is the author/funder, who has granted bioRxiv a license to display the preprint in perpetuity. It is made available under aCC-BY 4.0 International license.

\section{Acknowledgements}

We thank members of the lab for discussions and critical reading of the manuscript. This project was supported by the Swiss National Science Foundation and the NCCR Brain Plasticity and Repair (Center of Transgenesis

Expertise). 


\section{References}

Andermatt, I., and Stoeckli, E.T. (2014). RNAi-based gene silencing in chicken brain development. Methods in molecular biology 1082, 253-266.

Andermatt, I., Wilson, N.H., Bergmann, T., Mauti, O., Gesemann, M., Sockanathan, S., and Stoeckli, E.T. (2014). Semaphorin 6B acts as a receptor in post-crossing commissural axon guidance. Development 141, 3709-3720.

Augsburger, A., Schuchardt, A., Hoskins, S., Dodd, J., and Butler, S. (1999). BMPs as mediators of roof plate repulsion of commissural neurons. Neuron $24,127-141$.

Avilés, E.C., and Stoeckli, E.T. (2016). Canonical wnt signaling is required for commissural axon guidance. Developmental Neurobiology 76, 190-208.

Baeriswyl, T., Mauti, O., and Stoeckli, E.T. (2008). Temporal control of gene silencing by in ovo electroporation. Methods in molecular biology 442, 231-244.

Baeriswyl, T., and Stoeckli, E.T. (2008). Axonin-1/TAG-1 is required for pathfinding of granule cell axons in the developing cerebellum. Neural Development 3, 7.

Blockus, H., and Chédotal, A. (2016). Slit-Robo signaling. Development 143, 3037-3044.

Bourikas, D., Pekarik, V., Baeriswyl, T., Grunditz, A., Sadhu, R., Nardó, M., and Stoeckli, E.T. (2005). Sonic hedgehog guides commissural axons along the longitudinal axis of the spinal cord. Nature neuroscience 8, 297304.

Boyer, N.P., and Gupton, S.L. (2018). Revisiting Netrin-1. One Who Guides (Axons). Frontiers in cellular neuroscience 12, 221.

Brusés, J.L., and Rutishauser, U. (2001). Roles, regulation, and mechanism of polysialic acid function during neural development. Biochimie 83, 635-643.

Burgess, A., Wainwright, S.R., Shihabuddin, L.S., Rutishauser, U., Seki, T., and Aubert, I. (2008). Polysialic acid regulates the clustering, migration, and neuronal differentiation of progenitor cells in the adult hippocampus. Developmental Neurobiology 68, 1580-1590.

Charoy, C., Nawabi, H., Reynaud, F., Derrington, E., Bozon, M., Wright, K., Falk, J., Helmbacher, F., Kindbeiter, K., and Castellani, V. (2012). gdnf activates midline repulsion by Semaphorin3B via NCAM during commissural axon guidance. Neuron 75, 1051-1066.

Dahmane, N., and Ruiz i Altaba, A. (1999). Sonic hedgehog regulates the growth and patterning of the cerebellum. Development 126, 3089-3100. 
De Ramon Francàs, G., Zuñiga, N.R., and Stoeckli, E.T. (2017). The spinal cord shows the way - How axons navigate intermediate targets. Developmental biology 432, 43-52.

Dessaud, E., McMahon, A.P., and Briscoe, J. (2008). Pattern formation in the vertebrate neural tube. A sonic hedgehog morphogen-regulated transcriptional network. Development 135, 2489-2503.

Domanitskaya, E., Wacker, A., Mauti, O., Baeriswyl, T., Esteve, P., Bovolenta, P., and Stoeckli, E.T. (2010). Sonic hedgehog guides post-crossing commissural axons both directly and indirectly by regulating Wnt activity. The Journal of neuroscience : the official journal of the Society for Neuroscience 30, 11167-11176.

Doyonnas, R., Kershaw, D.B., Duhme, C., Merkens, H., Chelliah, S., Graf, T., and McNagny, K.M. (2001). Anuria, omphalocele, and perinatal lethality in mice lacking the CD34-related protein podocalyxin. The Journal of experimental medicine 194, 13-27.

Doyonnas, R., Nielsen, J.S., Chelliah, S., Drew, E., Hara, T., Miyajima, A., and McNagny, K.M. (2005). Podocalyxin is a CD34-related marker of murine hematopoietic stem cells and embryonic erythroid cells. Blood 105, 41704178.

Fitzli, D., Stoeckli, E.T., Kunz, S., Siribour, K., Rader, C., Kunz, B., Kozlov, S.V., Buchstaller, A., Lane, R.P., Suter, D.M., Dreyer, W.J., and Sonderegger, P. (2000). A Direct Interaction of Axonin-1 with Ngcam-Related Cell Adhesion Molecule (Nrcam) Results in Guidance, but Not Growth of Commissural Axons. The Journal of Cell Biology 149, 951-968.

Furness, S.G.B., and McNagny, K. (2006). Beyond mere markers. Functions for CD34 family of sialomucins in hematopoiesis. Immunologic research 34, 13-32.

Gomez, T.M., and Letourneau, P.C. (2014). Actin dynamics in growth cone motility and navigation. Journal of neurochemistry 129, 221-234.

Hamburger, V., and Hamilton, H.L. (1951). A series of normal stages in the development of the chick embryo. Journal of morphology 88, 49-92.

Hatten, M.E. (1999). Central nervous system neuronal migration. Annual review of neuroscience 22, 511-539.

Islam, S.M., Shinmyo, Y., Okafuji, T., Su, Y., Naser, I.B., Ahmed, G., Zhang, S., Chen, S., Ohta, K., Kiyonari, H., Abe, T., Tanaka, S., Nishinakamura, R., Terashima, T., Kitamura, T., and Tanaka, H. (2009). Draxin, a repulsive guidance protein for spinal cord and forebrain commissures. Science (New York, N.Y.) 323, 388-393.

Kerjaschki, D., Sharkey, D.J., and Farquhar, M.G. (1984). Identification and characterization of podocalyxin--the major sialoprotein of the renal glomerular epithelial cell. The Journal of Cell Biology 98, 1591-1596.

Landmesser, L., Dahm, L., Tang, J.C., and Rutishauser, U. (1990). Polysialic acid as a regulator of intramuscular nerve branching during embryonic development. Neuron 4, 655-667. 
Lewis, P.M., Gritli-Linde, A., Smeyne, R., Kottmann, A., and McMahon, A.P. (2004). Sonic hedgehog signaling is required for expansion of granule neuron precursors and patterning of the mouse cerebellum. Developmental biology $270,393-410$.

Long, H., Sabatier, C., Le Ma, Plump, A., Yuan, W., Ornitz, D.M., Tamada, A., Murakami, F., Goodman, C.S., and Tessier-Lavigne, M. (2004). Conserved roles for Slit and Robo proteins in midline commissural axon guidance. Neuron 42, 213-223.

Lyuksyutova, A.I., Lu, C.-C., Milanesio, N., King, L.A., Guo, N., Wang, Y., Nathans, J., Tessier-Lavigne, M., and Zou, Y. (2003). Anterior-posterior guidance of commissural axons by Wnt-frizzled signaling. Science (New York, N.Y.) $302,1984-1988$.

Mauti, O., Sadhu, R., Gemayel, J., Gesemann, M., and Stoeckli, E.T. (2006). Expression patterns of plexins and neuropilins are consistent with cooperative and separate functions during neural development. BMC Developmental Biology 6, 32.

Nawabi, H., Briançon-Marjollet, A., Clark, C., Sanyas, I., Takamatsu, H., Okuno, T., Kumanogoh, A., Bozon, M., Takeshima, K., Yoshida, Y., Moret, F., Abouzid, K., and Castellani, V. (2010). A midline switch of receptor processing regulates commissural axon guidance in vertebrates. Genes \& Development 24, 396-410.

Nielsen, J.S., Graves, M.L., Chelliah, S., Vogl, A.W., Roskelley, C.D., and McNagny, K.M. (2007). The CD34-related molecule podocalyxin is a potent inducer of microvillus formation. PloS one 2, e237.

Nielsen, J.S., and McNagny, K.M. (2008). Novel functions of the CD34 family. Journal of cell science 121, 36833692.

Nielsen, J.S., and McNagny, K.M. (2009). The role of podocalyxin in health and disease. Journal of the American Society of Nephrology : JASN 20, 1669-1676.

Parra, L.M., and Zou, Y. (2010). Sonic hedgehog induces response of commissural axons to Semaphorin repulsion during midline crossing. Nature neuroscience 13, 29-35.

Pekarik, V., Bourikas, D., Miglino, N., Joset, P., Preiswerk, S., and Stoeckli, E.T. (2003). Screening for gene function in chicken embryo using RNAi and electroporation. Nature biotechnology 21, 93-96.

Philipp, M., Niederkofler, V., Debrunner, M., Alther, T., Kunz, B., and Stoeckli, E.T. (2012). RabGDI controls axonal midline crossing by regulating Robo1 surface expression. Neural Development 7, 36.

Ruiz de Almodovar, C., Fabre, P.J., Knevels, E., Coulon, C., Segura, I., Haddick, P.C.G., Aerts, L., Delattin, N., Strasser, G., Oh, W.-J., Lange, C., Vinckier, S., Haigh, J., Fouquet, C., Henderson, C., Gu, C., Alitalo, K., Castellani, V., Tessier-Lavigne, M., Chedotal, A., Charron, F., and Carmeliet, P. (2011). VEGF mediates commissural axon chemoattraction through its receptor Flk1. Neuron 70, 966-978. 
Rutishauser, U., Acheson, A., Hall, A.K., Mann, D.M., and Sunshine, J. (1988). The neural cell adhesion molecule (NCAM) as a regulator of cell-cell interactions. Science (New York, N.Y.) 240, 53-57.

Rutishauser, U. (2008). Polysialic acid in the plasticity of the developing and adult vertebrate nervous system. Nature reviews. Neuroscience 9, 26-35.

Sassetti, C., van Zante, A., and Rosen, S.D. (2000). Identification of endoglycan, a member of the CD34/podocalyxin family of sialomucins. The Journal of biological chemistry 275, 9001-9010.

Short, C.A., Suarez-Zayas, E.A., and Gomez, T.M. (2016). Cell adhesion and invasion mechanisms that guide developing axons. Current opinion in neurobiology 39, 77-85.

Stoeckli, E.T., and Landmesser, L.T. (1995). Axonin-1, Nr-CAM, and Ng-CAM play different roles in the in vivo guidance of chick commissural neurons. Neuron 14, 1165-1179.

Stoeckli, E.T., Sonderegger, P., Pollerberg, G.E., and Landmesser, L.T. (1997). Interference with axonin-1 and NrCAM interactions unmasks a floor-plate activity inhibitory for commissural axons. Neuron 18, $209-221$.

Stoeckli, E. (2017). Where does axon guidance lead us? F1000Research 6.

Stoeckli, E.T. (2010). Neural circuit formation in the cerebellum is controlled by cell adhesion molecules of the Contactin family. Cell Adhesion \& Migration 4, 523-526.

Stoeckli, E.T. (2018). Understanding axon guidance. Are we nearly there yet? Development 145.

Takeda, T., Go, W.Y., Orlando, R.A., and Farquhar, M.G. (2000). Expression of podocalyxin inhibits cell-cell adhesion and modifies junctional properties in Madin-Darby canine kidney cells. Molecular biology of the cell 11, 3219-3232.

Tang, J., Landmesser, L., and Rutishauser, U. (1992). Polysialic acid influences specific pathfinding by avian motoneurons. Neuron 8, 1031-1044.

Tang, J., Rutishauser, U., and Landmesser, L. (1994). Polysialic acid regulates growth cone behavior during sorting of motor axons in the plexus region. Neuron 13, 405-414.

Vitureira, N., Andrés, R., Pérez-Martínez, E., Martínez, A., Bribián, A., Blasi, J., Chelliah, S., López-Doménech, G., Castro, F. de, Burgaya, F., McNagny, K., and Soriano, E. (2010). Podocalyxin is a novel polysialylated neural adhesion protein with multiple roles in neural development and synapse formation. PloS one 5, e12003.

Vitureira, N., McNagny, K., Soriano, E., and Burgaya, F. (2005). Pattern of expression of the podocalyxin gene in the mouse brain during development. Gene expression patterns : GEP 5, 349-354.

Wallace, V.A. (1999). Purkinje-cell-derived Sonic hedgehog regulates granule neuron precursor cell proliferation in the developing mouse cerebellum. Current biology : CB 9, 445-448. 
Wechsler-Reya, R.J., and Scott, M.P. (1999). Control of neuronal precursor proliferation in the cerebellum by Sonic Hedgehog. Neuron 22, 103-114.

Wilson, N.H., and Stoeckli, E.T. (2011). Cell type specific, traceable gene silencing for functional gene analysis during vertebrate neural development. Nucleic Acids Research 39, e133.

Wilson, N.H., and Stoeckli, E.T. (2012). In ovo Electroporation of miRNA-based Plasmids in the Developing Neural Tube and Assessment of Phenotypes by Dil Injection in Open-book Preparations. Journal of Visualized Experiments : JoVE.

Wilson, N.H., and Stoeckli, E.T. (2013). Sonic hedgehog regulates its own receptor on postcrossing commissural axons in a glypican1-dependent manner. Neuron 79, 478-491.

Yaginuma, H., Homma, S., Künzi, R., and Oppenheim, R.W. (1991). Pathfinding by growth cones of commissural interneurons in the chick embryo spinal cord. A light and electron microscopic study. The Journal of comparative neurology 304, 78-102.

Yam, P.T., Kent, C.B., Morin, S., Farmer, W.T., Alchini, R., Lepelletier, L., Colman, D.R., Tessier-Lavigne, M., Fournier, A.E., and Charron, F. (2012). 14-3-3 proteins regulate a cell-intrinsic switch from sonic hedgehogmediated commissural axon attraction to repulsion after midline crossing. Neuron 76, 735-749.

Yam, P.T., Langlois, S.D., Morin, S., and Charron, F. (2009). Sonic hedgehog guides axons through a noncanonical, Src-family-kinase-dependent signaling pathway. Neuron 62, 349-362.

Zou, Y., Stoeckli, E., Chen, H., and Tessier-Lavigne, M. (2000). Squeezing axons out of the gray matter. A role for slit and semaphorin proteins from midline and ventral spinal cord. Cell 102, 363-375. 


\section{Figure 1}
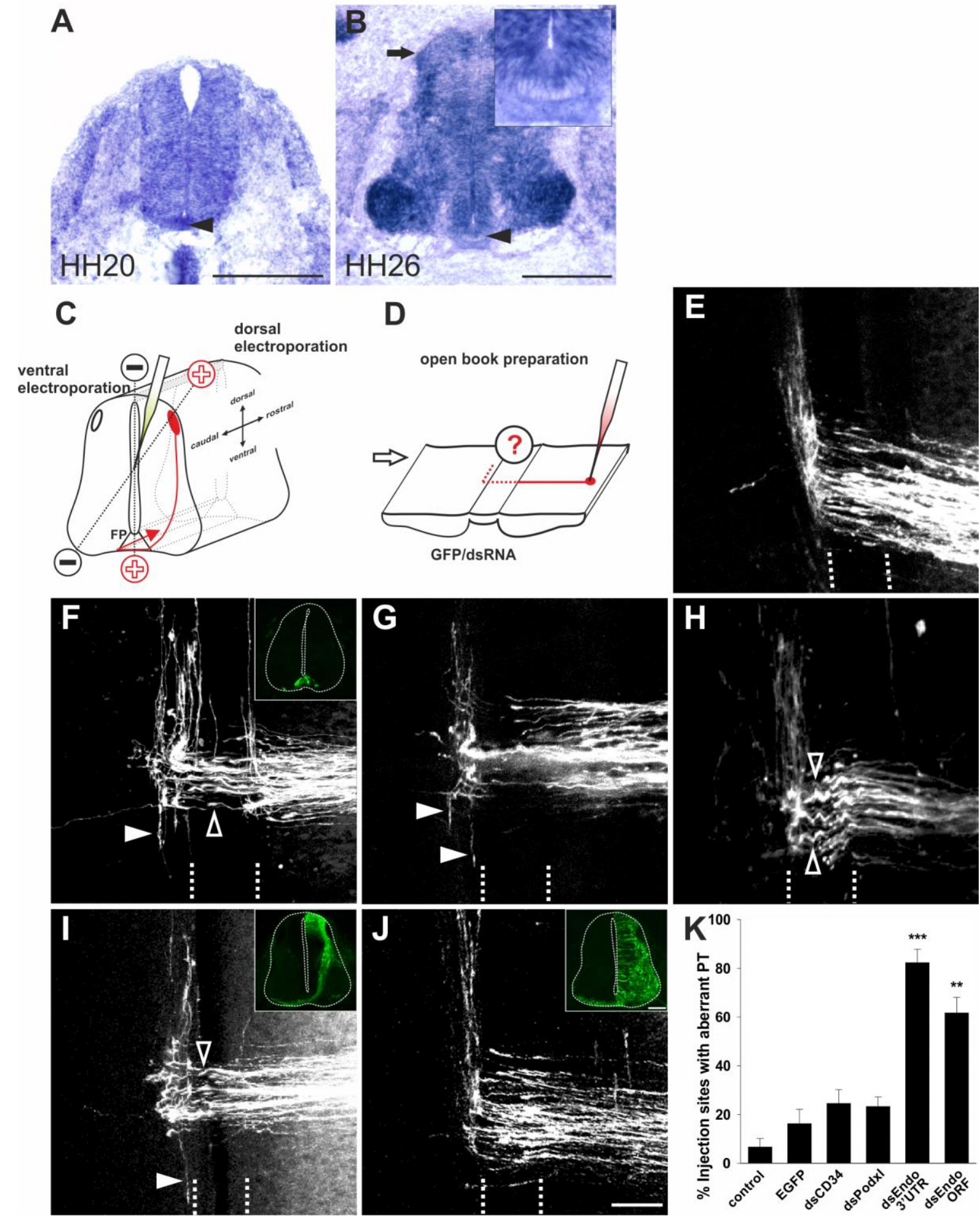

Figure 1

Endoglycan is required for the correct turning of post-crossing commissural axons. 
$(A, B)$ Endoglycan is expressed in the developing neural tube during commissural axon guidance. Endoglycan is expressed throughout the neural tube at $\mathrm{HH} 20$ (A). Higher levels are seen in the floor plate (arrowhead). (B) At $\mathrm{HH} 26$, Endoglycan is still found in most cells of the spinal cord. High levels are found in motoneurons and interneurons, including the dorsal dI1 neurons (arrow), and in the floor plate (arrowhead and insert in B). Commissural axon pathfinding was analyzed in "open-book" preparations (C,D; see Methods for details). The positions of the electrodes for dorsal and ventral electroporation are indicated (C). In control embryos at $\mathrm{HH} 26$, commissural axons have crossed the floor plate and turned rostrally along the contralateral floor-plate border (E). In contrast, after downregulation of Endoglycan (F-I) commissural axons failed to turn along the contralateral floor-plate border or they turned randomly either rostrally or caudally (arrowheads in F-I). Occasionally axons were turning already inside the floor plate (open arrowhead in F). A closer look at the morphology of the axons in the floor plate revealed their tortuous, 'corkscew-like' trajectory across the midline at many Dil injection sites (open arrowheads in $\mathrm{H}$ ).

To knockdown Endoglycan either in the floor plate or in commissural neurons the ventral or dorsal spinal cord was targeted as indicated in (C) (see inserts in F and I, respectively). Phenotypes were the same as those observed after targeting the floor plate $(F)$ or one half of the spinal cord including the floor plate $((G, H)$. Pathfinding was normal in embryos electroporated with dsRNA derived from Podocalyxin (J).

The quantification of injection sites with pathfinding errors after targeting the floor plate or one half of the spinal cord is shown in (K). Pathfinding errors were seen only at $6.7 \pm 3.4 \%$ of the injection sites in untreated control embryos ( $n=10$ embryos, 45 injection sites). In control embryos injected and electroporated with the EGFP plasmid alone pathfinding errors were found at $16.2 \pm 6 \%$ of the injection sites ( $n=17$ embryos, 92 injection sites). Injection and electroporation of dsRNA derived from $C D 34(24.6 \pm 5.8 \%, \mathrm{n}=8$ embryos, 80 injection sites) and Podocalyxin (23.3 $\pm 3.9 \%, n=17$ embryos, 147 injection sites) did not affect midline crossing and turning behavior of commissural axons. In contrast, $82.3 \pm 5.6 \%$ ( $n=11$ embryos, 65 sites) and $61.7 \pm 6.4 \%$ ( $n=18,161$ sites) of the injection sites in embryos injected with dsRNA derived from the 3'-UTR or the ORF of Endoglycan, respectively, showed aberrant pathfinding of commissural axons. P values $* * *<0.001$ and $* *<0.01$, respectively, compared to EGFP-injected control groups, respectively. The two groups electroporated with dsRNA derived from Endoglycan were not different from each other. Bar: $50 \mu \mathrm{m}$ in B-G; $100 \mu \mathrm{m}$ in inserts. 
Figure 2

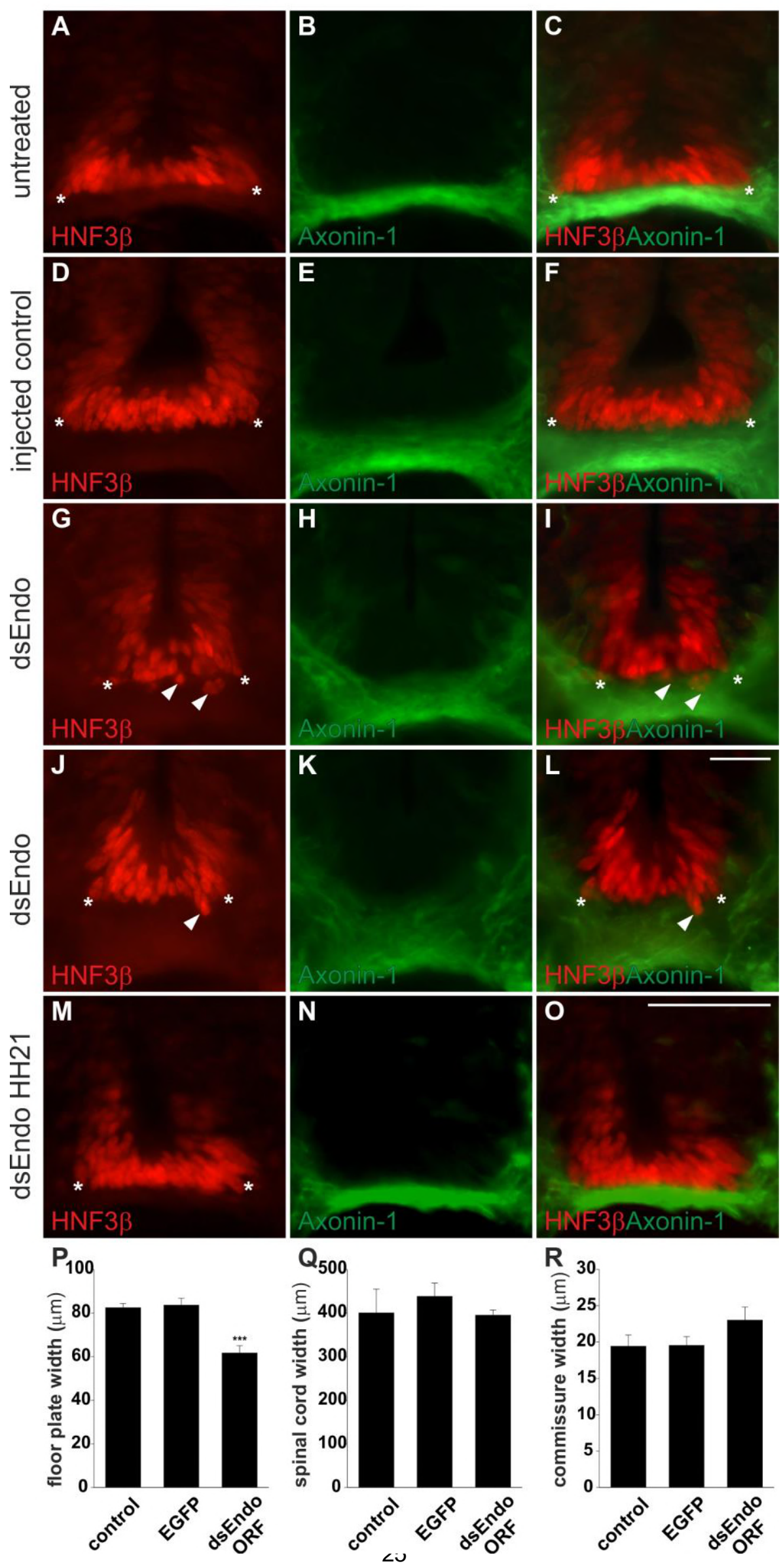


Figure 2

\section{After downregulation of Endoglycan the morphology of the floor plate is compromised.}

In untreated $(A-C)$ and control-treated embryos (D-F) the floor plate is of triangular shape with floor-plate cells precisely aligned at the ventral border. There is no overlap between the floor plate (visualized by HNF3 $\beta$ staining; red) and the commissure (visualized by anti-Axonin1 staining; green). The shape of the floor plate is no longer triangular in embryos lacking Endoglycan (G-L). The floor-plate cells are not aligned ventrally (arrowheads in G, I, J, and L) and the floor plate appears to have gaps. The width of the floor plate (indicated by asterisks) was measured (P). There was no significant difference in spinal cord width (Q), but floor plates were significantly narrower in embryos lacking Endoglycan $(61.6 \pm 3.4 \mu \mathrm{m} ; \mathrm{n}=7$ embryos; $\mathrm{p}<0.001)$ compared to untreated $(82.4 \pm 2.0 \mu \mathrm{m} ; \mathrm{n}=6$ embryos) and EGFP-injected control embryos (83.6 $\pm 3.2 \mu \mathrm{m} ; \mathrm{n}=6$ embryos). The commissure had a tendency to be wider in experimental compared to control embryos but the effect was not statistically significant (R). The changes in floor-plate morphology were only seen at $\mathrm{HH} 26(\mathrm{~A}-\mathrm{L})$, after axons had crossed the floor plate. When the floor-plate morphology was analyzed at $\mathrm{HH} 21$, when commissural axons have reached but only few have crossed the midline, no dislocated cells and no gaps in the floor plate were observed (M-O). The width of the floor plate was not different when measured at $\mathrm{HH} 21 / 22$ with $70.1 \pm 4.2 \mu \mathrm{m}$ for untreated and $70.6 \pm 2.5 \mu \mathrm{m}$ for EGFP controls, compared to $71.8 \pm 2.0 \mu \mathrm{m}$ for experimental embryos. Bar: 50 $\mu \mathrm{m}$. 


\section{Figure 3}

\section{A}

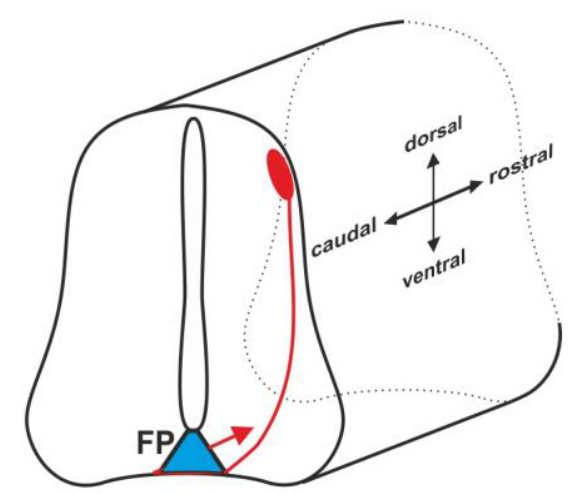

B

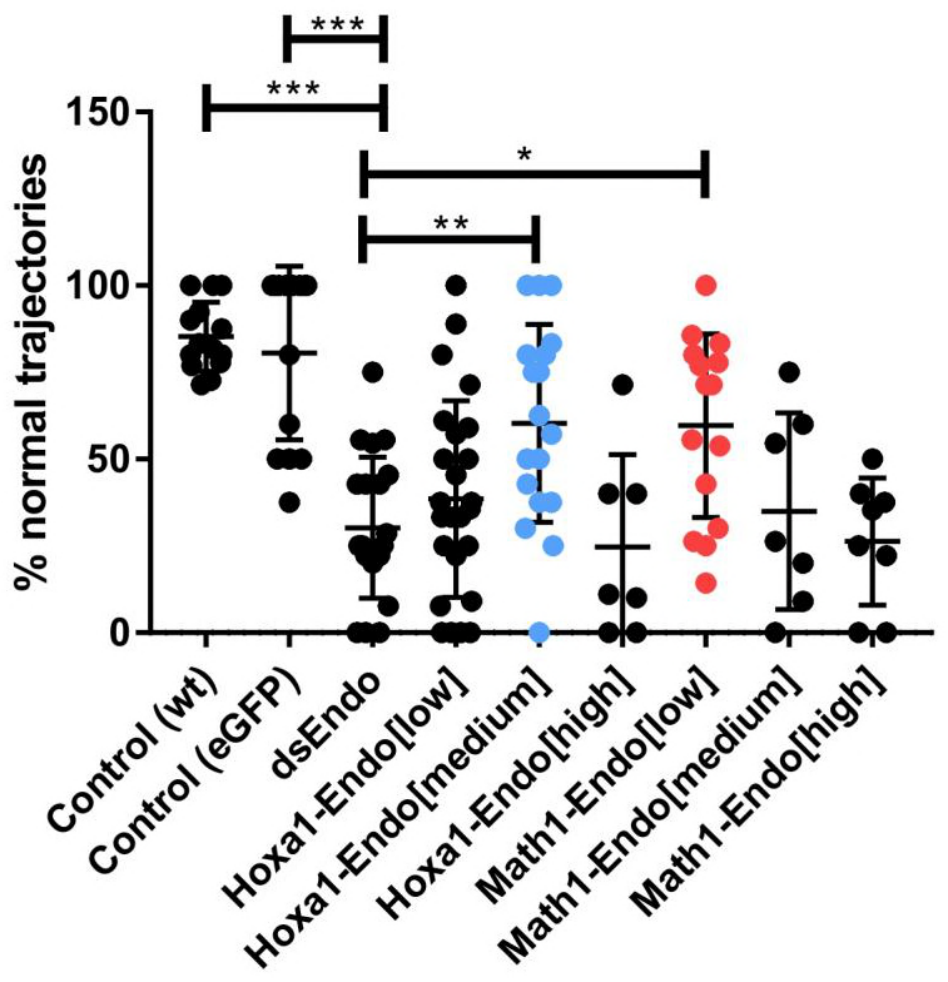

Figure 3

\section{Too much or too little Endoglycan causes aberrant axon guidance}

Because silencing Endoglycan either in commissural neurons or in the floor plate caused the same type of axon guidance defects, we wanted to test the idea that the presence of an adequate amount but not the source of Endoglycan was important. We therefore downregulated Endoglycan by the transfection of dsRNA derived 
from the 3'UTR of Endoglycan in the entire spinal cord. We then tried to rescue the aberrant axon guidance phenotype by the electroporation of the Endoglycan ORF specifically in dl1 neurons (using the Math1 promoter) or in the floor plate (using the Hoxa1 promoter). The rescue construct were used at a concentration of 150 (low), 300 (medium), and 750 (high) ng/ $\mu$ l, respectively. In both cases rescue was only possible with one concentration. The lowest concentration of the Hoxa1-driven construct and the two higher concentrations of the Math1-driven constructs were not able to rescue the aberrant phenotype. Statistical analysis by one-way ANOVA: $* p<0.05, * * p<0.01, * * * p<0.001$. See Table 1 for quantification. 
Figure 4
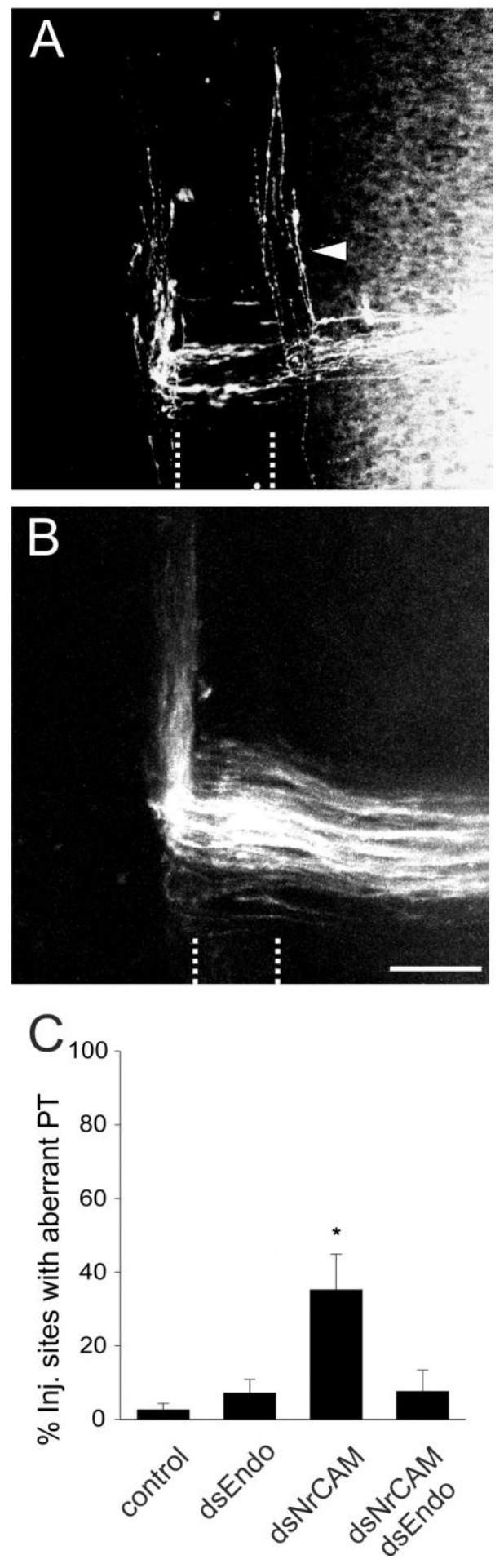

Figure 4

Endoglycan is a negative regulator of cell-cell adhesion in vivo and in vitro.

The perturbation of axon/floor-plate contact by downregulation of NrCAM resulted in the failure of commissural axons to enter the floor-plate area and caused their premature turns along the ipsilateral floor- 
plate border (arrowhead in A), as shown previously (Stoeckli and Landmesser, 1995; Philipp et al., 2012). If both NrCAM and Endoglycan were downregulated in the floor plate, the number of ipsilateral turns was reduced to control levels $(B, C)$, consistent with the idea that a decrease in adhesion due to a lack of NrCAM can be balanced by an increase in adhesion between floor plate and growth cone due to a lack of Endoglycan. Ipsilateral turns were rare in untreated control embryos $(2.6 \pm 1.7 \%, n=8$ embryos, 62 injection sites) and embryos lacking Endoglycan (7.1 $\pm 3.7 \%, n=7$ embryos, 51 injection sites). Ipsilateral turns were frequently found in the absence of $\operatorname{NrCAM}(35 \pm 9.8 \%, n=10$ embryos, 97 injection sites). Concomitant downregulation of NrCAM and Endoglycan reduced ipsilateral turns to $7.3 \pm 5.8 \%$ ( $n=10$ embryos; 78 injection sites). The floor plate is indicated by dashed lines in A,B. Bar: $50 \mu \mathrm{m}$. 

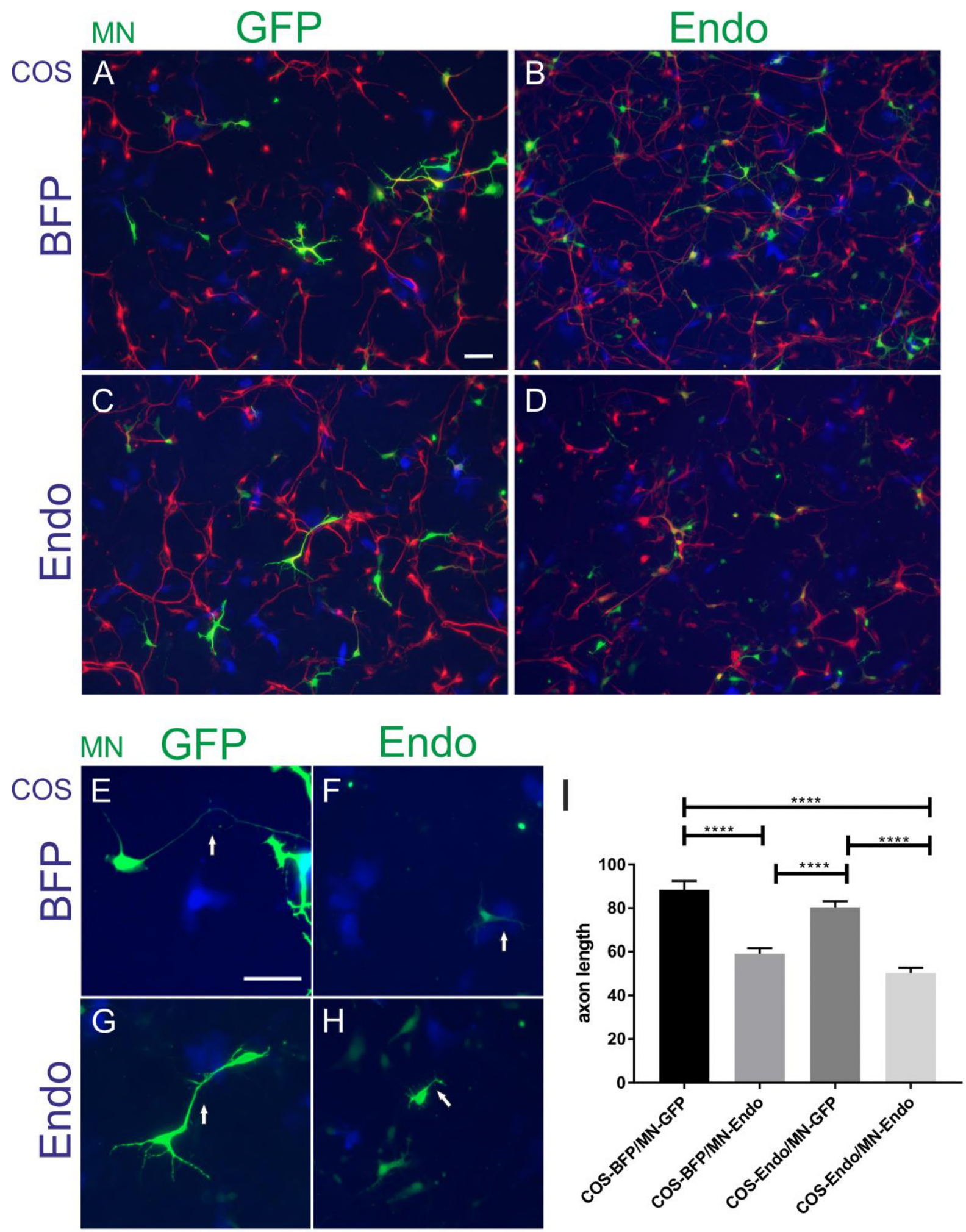

Figure 5

Overexpression of Endoglycan interferes with neurite outgrowth of motoneurons.

Dissociated motoneurons of $\mathrm{HH} 26$ embryos, either control embryos $(\mathrm{A}, \mathrm{C}, \mathrm{E}, \mathrm{G})$ or embryos overexpressing Endoglycan, $(\mathrm{B}, \mathrm{D}, \mathrm{F}, \mathrm{H})$ were cultured on either COS cells transfected with cDNA encoding BFP (blue fluorescent 

available under aCC-BY 4.0 International license.

protein; $A, B, E, F)$ or chicken Endoglycan $(C, D, G, H)$. Axon length was significantly reduced when motoneurons overexpressed Endoglycan (I). Overexpression of Endoglycan in COS cells had no effect on neurite length, most likely because neurites managed to grow in contact with control COS cells, as transfection efficiency was between 50 and $60 \% .{ }^{* * * *} p<0.0001$, one way ANOVA with Tukey's post-hoc test. Bar: $50 \mu \mathrm{m}$. 


\section{Figure 6}
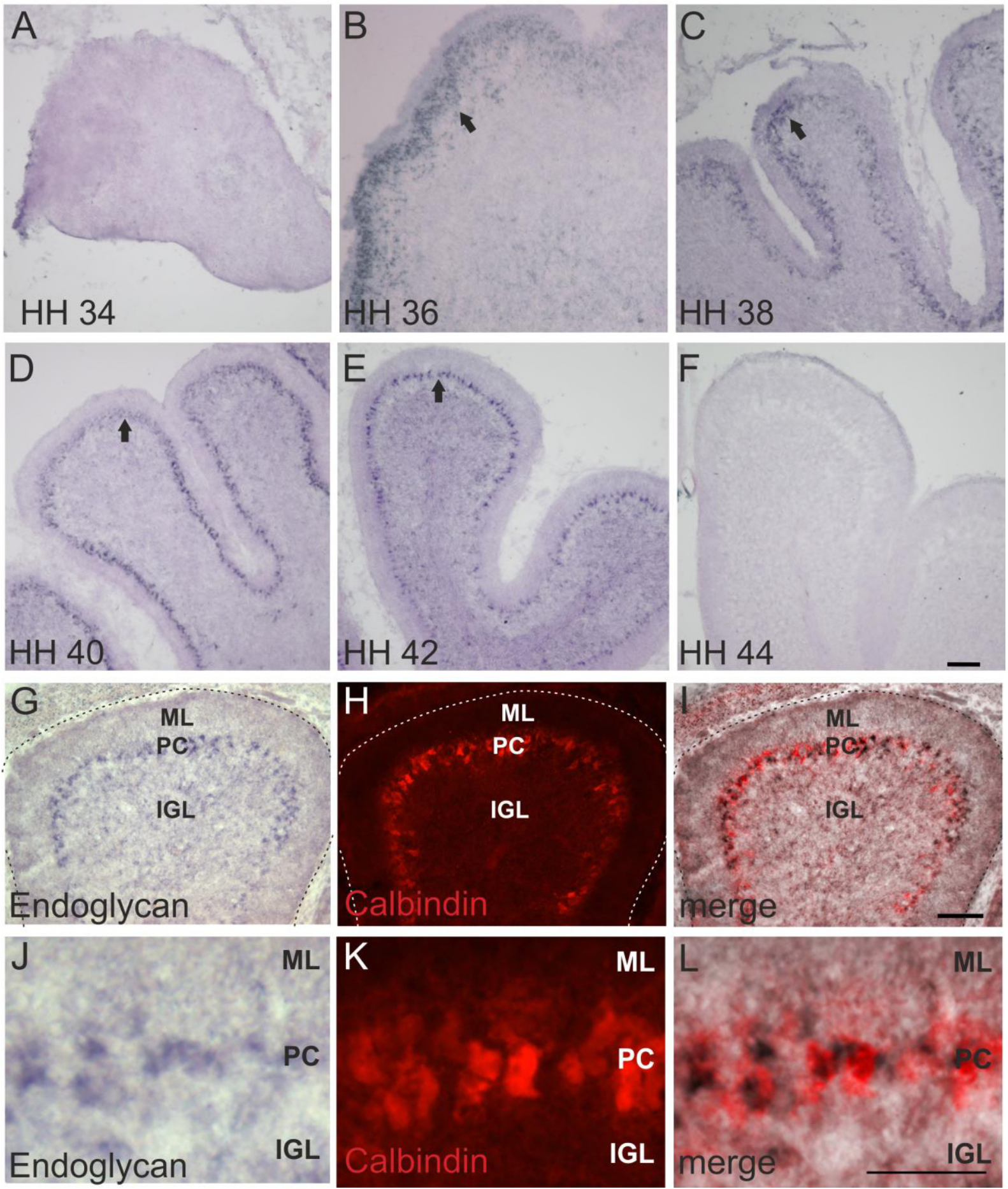

Figure 6

Endoglycan expression is restricted to Purkinje cells in the developing cerebellum. 
The temporal analysis of Endoglycan expression in the developing cerebellum localized it mainly to migrating Purkinje cells. No Endoglycan expression was found at HH34 (A). Starting at HH36 (B), Endoglycan mRNA was found in the developing cerebellum in migrating Purkinje cells. No change in expression was seen at $\mathrm{HH} 38$ (C), $\mathrm{HH} 40$ (D), and at HH42 (E) (arrows). At HH44, after migration of Purkinje cells was completed Endoglycan was no longer expressed (F). We used Calbindin to identify Purkinje cells (H,K). At HH38, the in situ signal for Endoglycan (G,J) co-localized with Calbindin staining (H,K; overlay in I,L). Bar: $100 \mu \mathrm{m}$ in A-F, $100 \mu \mathrm{m}$ in G-I, 50 $\mu \mathrm{m}$ in J-L. 
Figure 7
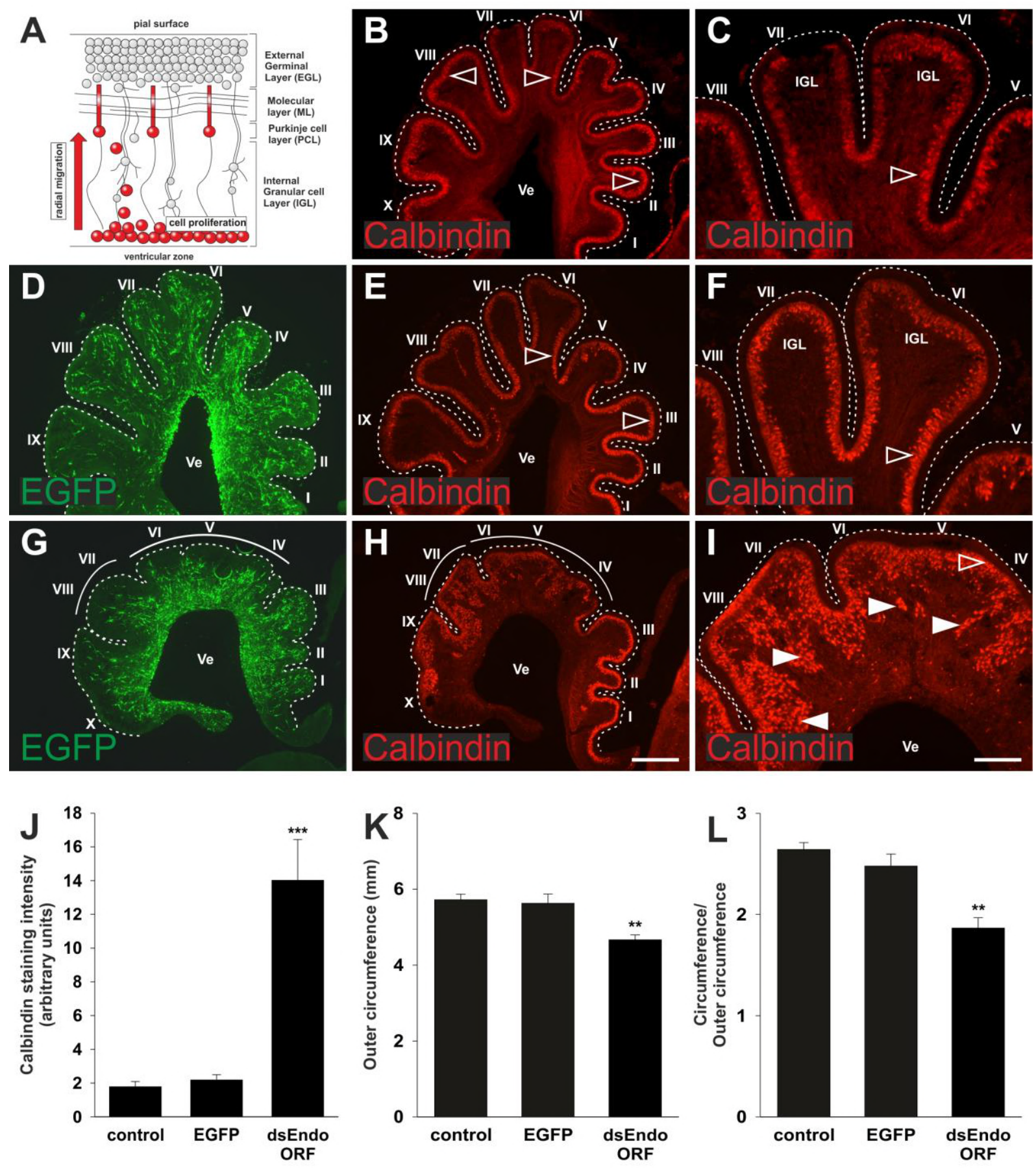

$M$ area of calbindin staining measured
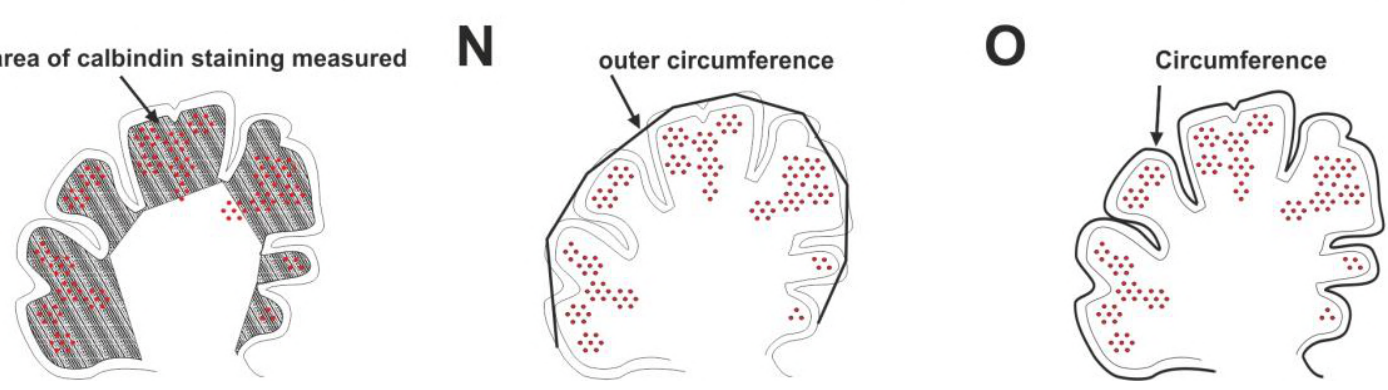

Figure 7

Endoglycan is required for Purkinje cell migration. 
Purkinje cells are born in the ventricular zone of the cerebellum. They migrate radially toward the periphery of the cerebellar folds to form the Purkinje cell layer (A). In control embryos at HH38, the Purkinje cell layer visualized by Calbindin staining is clearly detectable although not fully matured to a monolayer (B and C). Control-injected embryos (D-F) were not different from untreated control embryos. Calbindin stains Purkinje cells in the periphery of the cerebellar folds (E and F). In the absence of Endoglycan (G-I) Purkinje cells failed to migrate and remained stuck in the center of the cerebellar folds $(H$, arrowheads in $\mathrm{I})$. The failure of Purkinje cells to migrate radially was quantified by measuring fluorescence intensity for Calbindin in control ( $n=5$ embryos), EGFP-injected ( $\mathrm{n}=4$ embryos), and Endoglycan dsRNA-treated embryos ( $\mathrm{J} ; \mathrm{n}=5$ embryos). Calbindin staining intensity was measured as indicated in (M). The increase is highly significant for Endoglycan dsRNAtreated embryos, $p<0.001$. As a measure for the size of the cerebellum, the outer circumference was measured as indicated in $(\mathrm{N})$. The cerebellum was smaller in experimental embryos compared to both control groups $(K ; p<0.01)$. In order to quantify the reduction in the number of folds that was obvious from the visual inspection of cerebellar sections, we measured the actual circumference of the cerebellum as indicated in (O) and divided it by the outer circumference. Control embryos had a ratio of $2.64 \pm 0.06$ and $2.47 \pm 0.11$, respectively. Embryos lacking Endoglycan showed a clear reduction in the ratio between the two circumferences with a value of $1.8 \pm 0.1(\mathrm{~L} ; \mathrm{p}<0.01)$, indicating that they had fewer cerebellar folds compared to control embryos, which had always 10 distinct folds. Bar: $500 \mu \mathrm{m}$ in $\mathrm{B}, \mathrm{D}, \mathrm{E}, \mathrm{G}, \mathrm{H} ; 200 \mu \mathrm{m}$ in C, F, I. 
Figure 8

Control
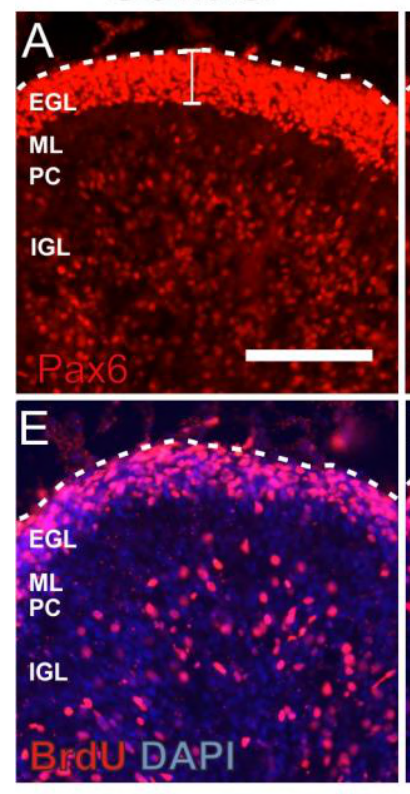

EGFP control
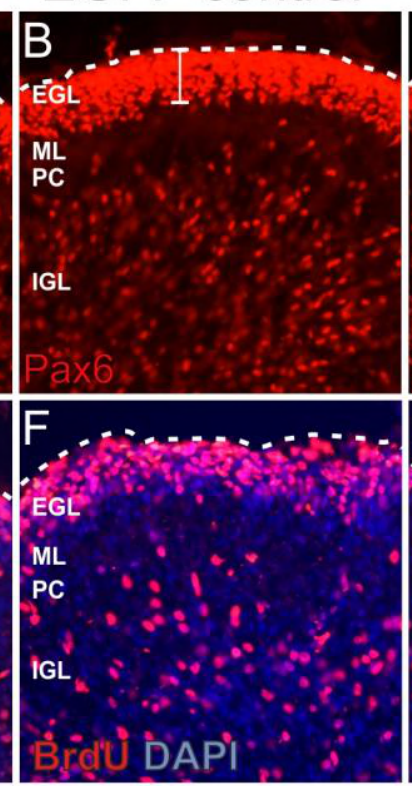

dsEndo

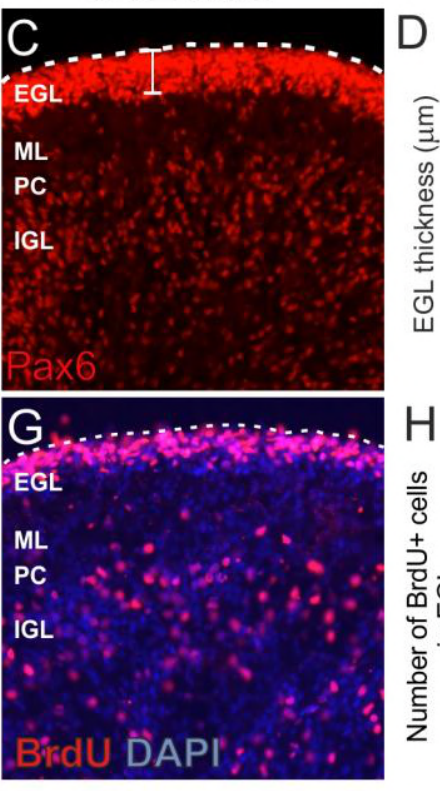

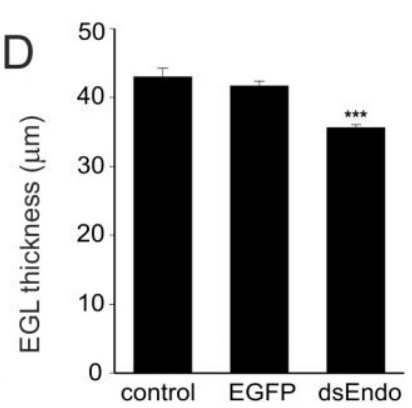

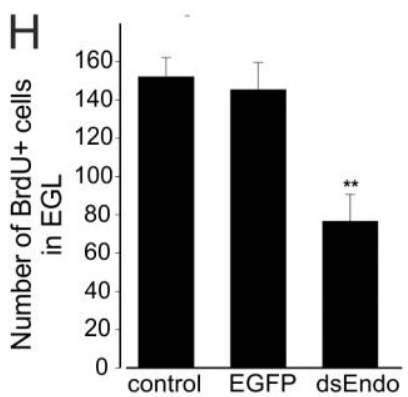

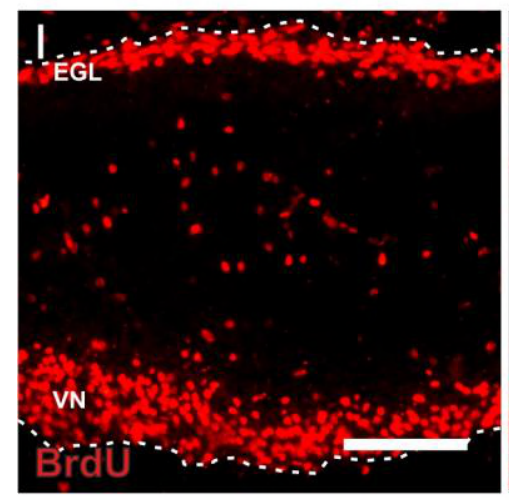
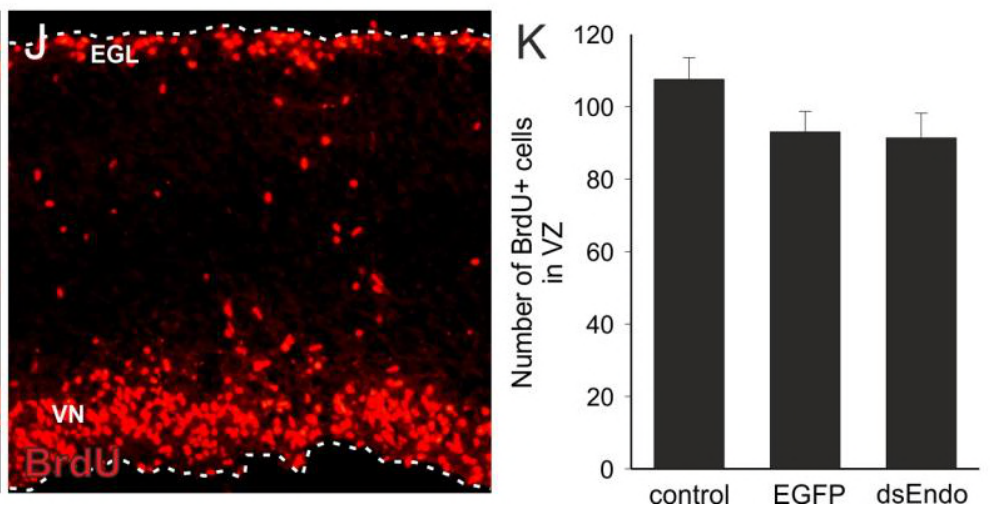

Figure 8

The reduced size of the cerebellum after downregulation of Endoglycan is due to reduced proliferation of granule cells.

The failure of Purkinje cell migration has negative consequences on granule cell proliferation $(A-H)$. Granule cells in the EGL and in the developing IGL are labeled by Pax6 (A-C). A reduction in the width of the EGL was found for embryos treated with dsRNA derived from Endoglycan $(C, D ; n=3$ embryos; $p<0.001)$ compared to age-matched untreated embryos $(A ; n=4$ embryos), or control-treated embryos, expressing EGFP ( $B ; n=3$ embryos), when sections from the same relative position of the cerebellum were analyzed. No difference was 
found between the two control groups (D). The proliferation of granule cells in the outer EGL was visualized by BrdU incorporation (E-H). Embryos were exposed to BrdU for 3 hours before they were sacrificed at HH38. The number of BrdU-positive cells in the outer EGL was compared between untreated ( $E$; $n=6$ embryos), EGFPexpressing control embryos ( $\mathrm{F} ; \mathrm{n}=4$ embryos) and embryos lacking Endoglycan ( $\mathrm{G} ; \mathrm{n}=5$ embryos). The number of BrdU-positive cells was significantly reduced in embryos lacking Endoglycan $(H ; p<0.01)$. The number of BrdU-positive cells in the ventricular zone at HH35 did not differ between untreated controls (I) and embryos lacking Endoglycan (J; K). The number of BrdU-positive cells in the ventricular zone is given per $10^{\prime} 000 \mu \mathrm{m}^{2}$. Bar: $100 \mu \mathrm{m}$.

Figure 9
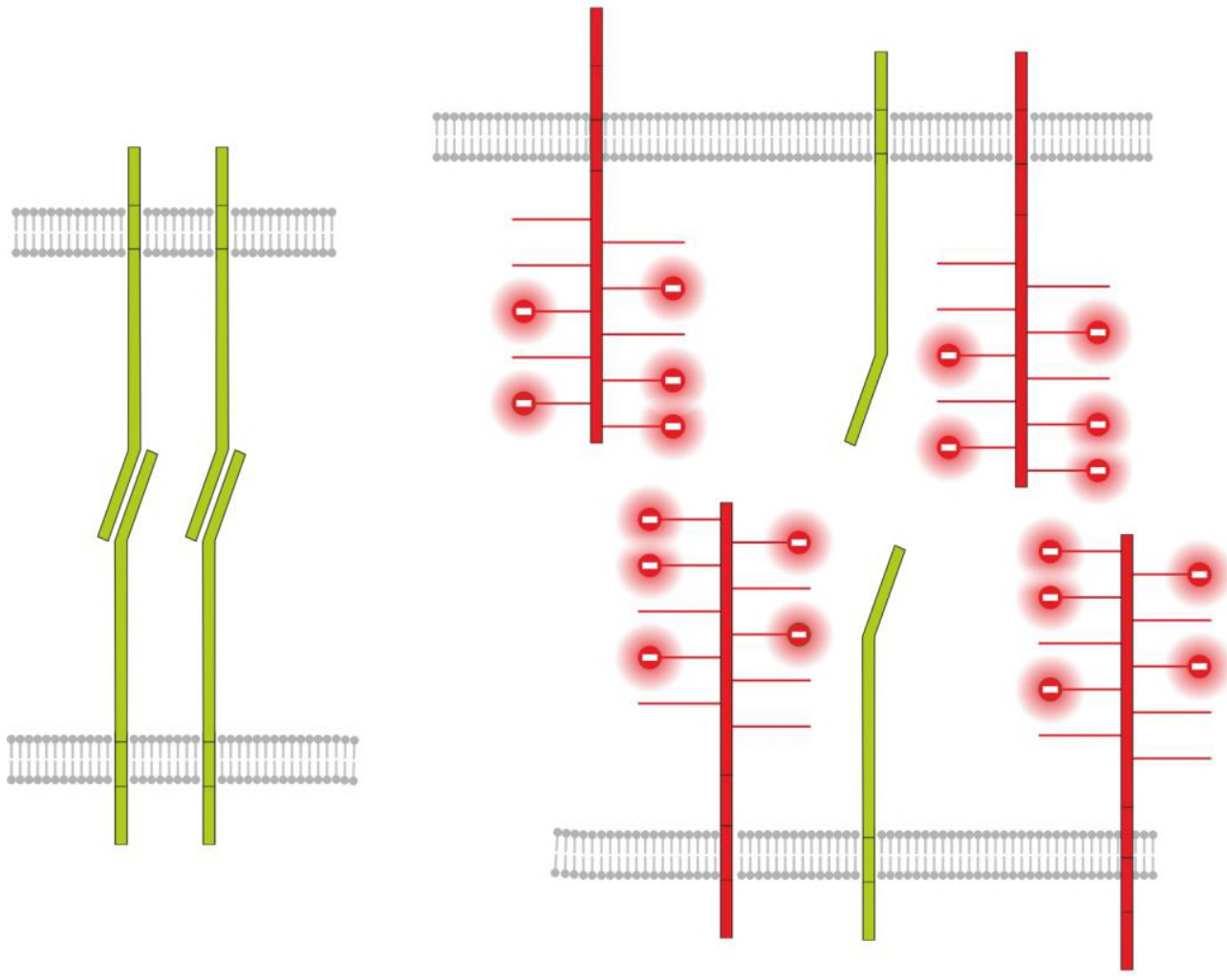

without Endoglycan

less adhesion with Endoglycan

Figure 9 


\section{Endoglycan modulates cell-cell contact by interference with adhesive strength}

Based on our in vivo and in vitro studies we postulate a model for Endoglycan function in neural circuit formation that suggests an 'anti-adhesive' role by modulation of many specific molecular interactions due to decreasing cell-cell contact. This model is consistent with our rescue experiments demonstrating that the source of Endoglycan did not matter but the expression level did. Thus, aberrant phenotypes were prevented when Endoglycan was expressed either in the axon or in the floor plate. 


\section{Supplementary Figures}

\section{Supplementary Figure 1}

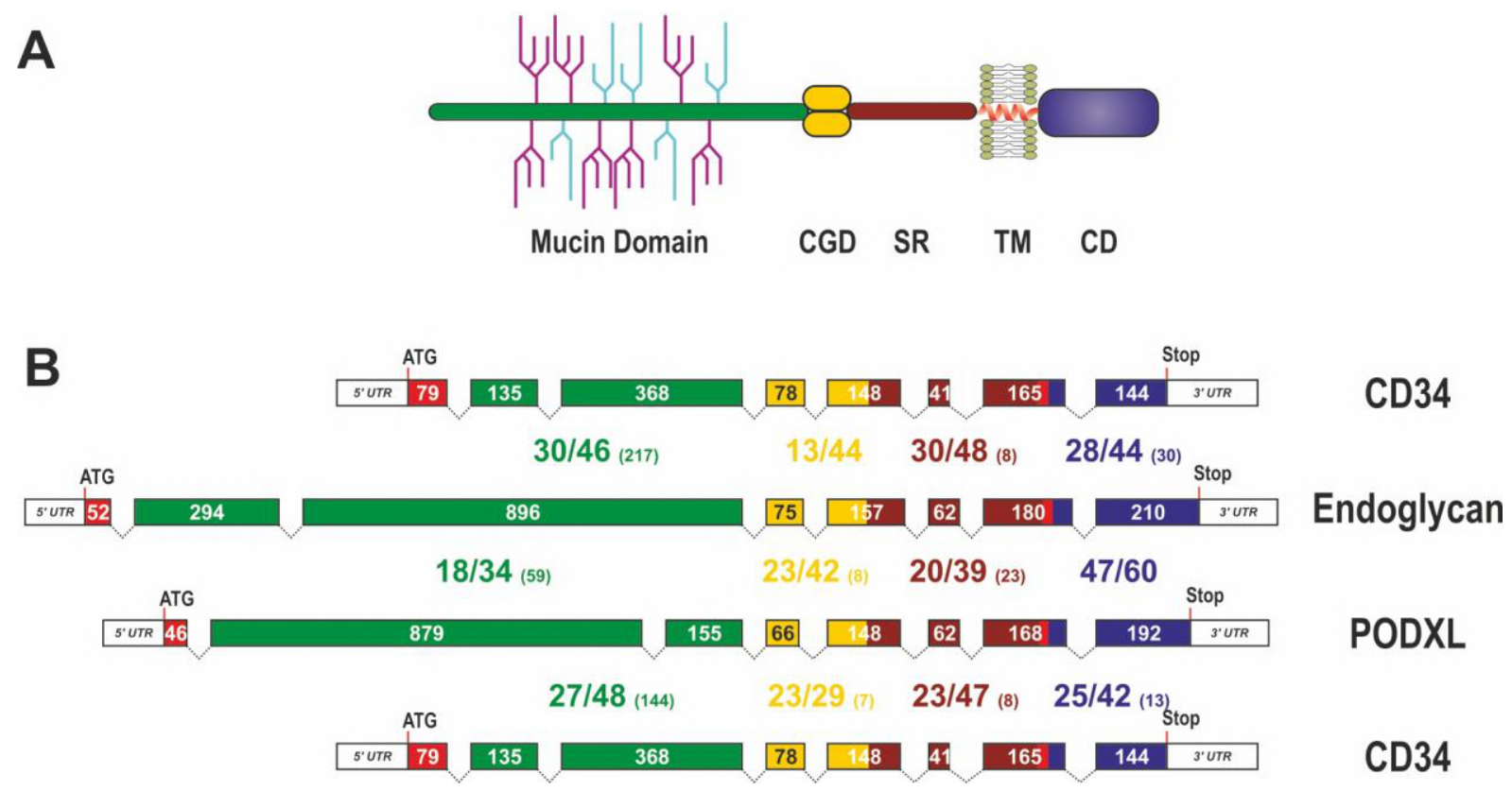

Supplementary Figure 1

Domain organization, exon alignment and conservation of the CD34 family of sialomucins

(A) Schematic of the domain organization of CD34 family members. They all contain an N-terminal, highly glycosylated, mucin domain (green), a cysteine-containing globular domain (CGD, yellow), a juxtamembrane stalk region (SR, brown), as well as a transmembrane alpha-helix (TM, red) and a cytoplasmic domain (CD, blue). O-linked glycosylation sites within the mucin domain are depicted in light blue, whereas further sialylated residues are symbolized in purple. N-linked glycosylation sites are not shown. Note, that the indicated glycosylation sites in this scheme are only symbolizing the extensive amount of glycosylation in sialomucins and are not representing the actual position of glycosylation. (B) Exon organization and domain conservation of sialomucins. Transcripts of CD34 family members are encoded by eight separate exons (colored boxes). While the length of exons coding for the cysteine containing globular domain (yellow), the juxtamembrane stalk region (brown), and the cytoplasmic domain (blue) are more or less conserved (exon sizes are given within the boxes), exons coding for the mucin domain (green) vary markedly in their length and organization. The translational start sites are highlighted by the ATG and the end of the coding sequences are 
indicated by the given Stop codon. Protein homology between the different chicken sialomucins is depicted by the large numbers between the exon pictograms. All domains were compared separately and the colors used indicate the corresponding domains. The first number indicates identical amino acids between the compared proteins, the second number represents conserved residues and the number in brackets designates the amount of gap positions within the alignment of the domains (eg. 28/44 (30)). The alignment was done using MUSCLE version 3.7. configured to the highest accuracy (Edgar, 2004). Single gap positions were scored with high penalties, whereas extensions of calculated gaps were less stringent. Using such parameters homologous regions of only distantly related sequences can be identified. Note, that within the mucin domain only some blocks, interspaced by sometimes large gap regions, are conserved between the different proteins.

\section{Supplementary Figure 2}

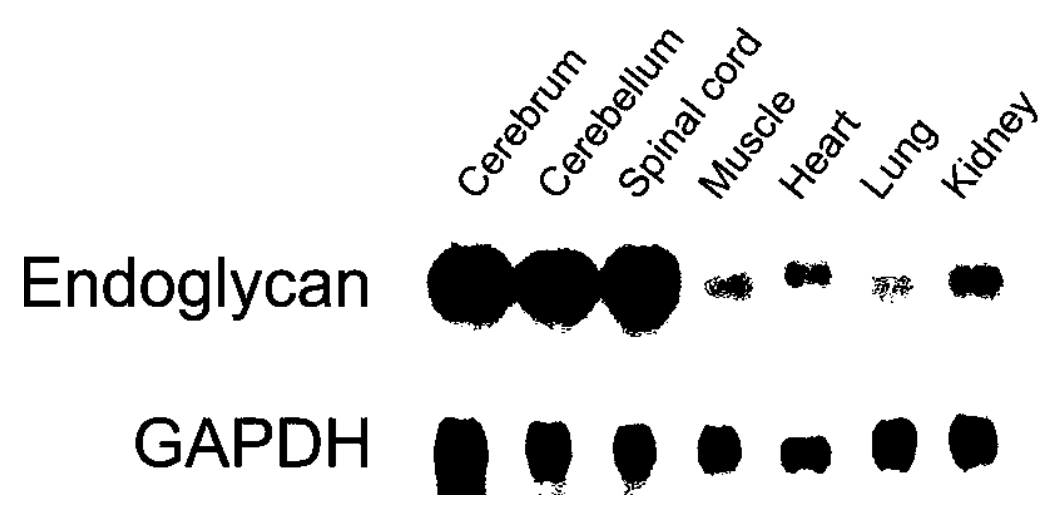

Supplementary Figure 2

\section{Endoglycan is mainly expressed in the developing nervous system}

Endoglycan is expressed only at low levels in non-neuronal tissues. Northern blot analysis of tissues taken from HH38 chicken embryos revealed its high expression levels in the cerebrum (brain without cerebellum), the 
cerebellum, and the spinal cord. Only low levels were found in muscle, heart, lung, and kidney. GAPDH was used as a loading control.

\section{Supplementary Figure 3}
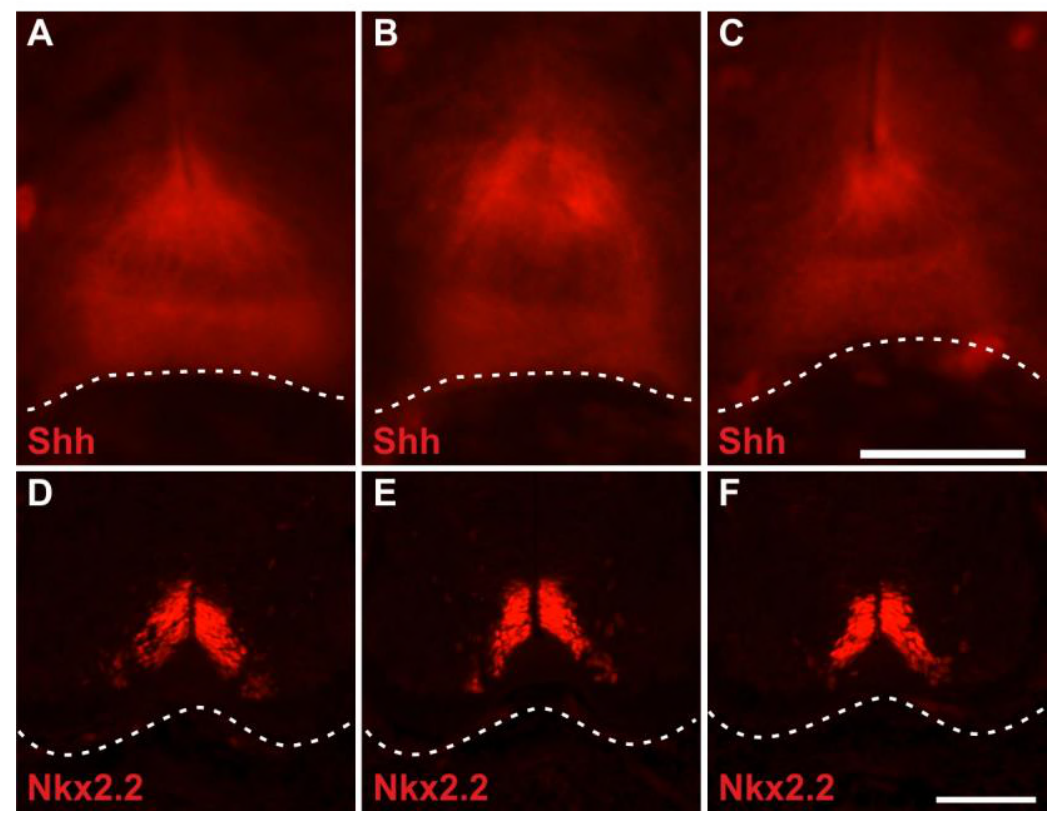

Supplementary Figure 3

\section{Downregulation of Endoglycan does not affect Shh expression or spinal cord patterning.}

Expression of Shh in the floor plate is required for spinal cord patterning during early stages of development

(Dessaud et al., 2008). Downregulation of Endoglycan by in ovo RNAi at HH18/19 did not abolish Shh expression in the floor plate at HH25/26. Shh expression in untreated (A) and control-treated (EGFP-expressing) embryos (B) was indistinguishable from embryos lacking Endoglycan (C). Note that the reduction in floor-plate width in embryos lacking Endoglycan (C; see Figure 2) can also be seen when Shh expression is analyzed. In agreement with our finding that the reduction in floor-plate width was a consequence of axon/floor-plate contact rather than a direct effect of Endoglycan on floor-plate morphology the patterning of the spinal cord was no different in embryos lacking Endoglycan (F) compared to non-treated (D) and control-treated embryos 
(E). Staining for Nkx2.2, a marker for ventral interneurons that is induced by Shh, was the same in all conditions. Bar: $50 \mu \mathrm{m}$.

\section{Supplementary Figure 4}
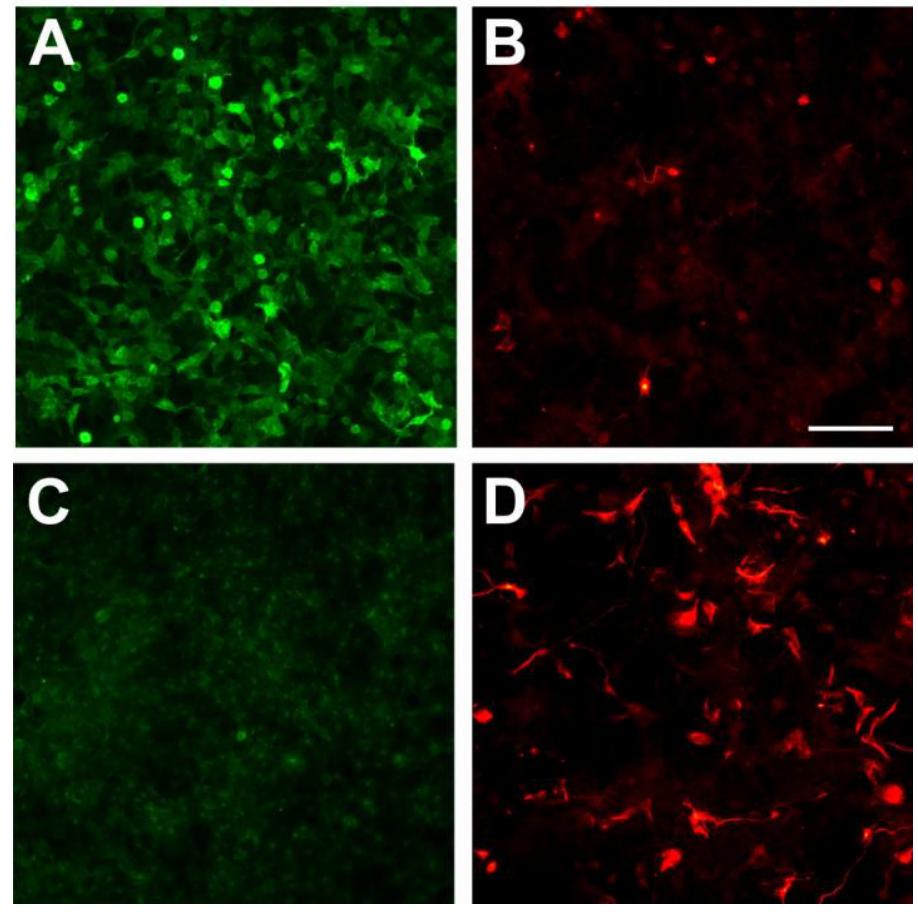

\section{Supplementary Figure 4}

\section{Endoglycan reduces adhesion of motoneurons}

HEK cells stably expressing human Endoglycan (A) or mock-transfected HEK cells (C) were used as carpet for motoneurons dissected from HH26 chicken embryos. Neurons were allowed to attach for $\mathrm{x}$ hours. Staining for Neurofilament revealed a pronounced decrease in the number of motoneurons on HEK cells expressing Endoglycan (B) compared to control HEK cells (D). Bar: $50 \mu \mathrm{m}$. 
Table 1

The source of Endoglycan does not matter

\begin{tabular}{|l|c|l|l|c|}
\hline Treatment & $\begin{array}{l}\text { No of } \\
\text { embryos }\end{array}$ & $\begin{array}{l}\text { No of } \\
\text { injection sites }\end{array}$ & $\begin{array}{l}\text { \% inj. sites with } \\
\text { normal PT }\end{array}$ & P-value \\
\hline Control (wt) & 14 & 111 & $85.3 \pm 2.6$ & 0.999 \\
\hline Control (eGFP) & 14 & 85 & $80.5 \pm 6.7$ & 1 \\
\hline dsEndo & 15 & 111 & $30.2 \pm 5.3$ & $<0.0001$ \\
\hline Hoxa1-endo[low] & 25 & 234 & $38.5 \pm 5.6$ & $<0.0001$ \\
\hline Hoxa1-endo[medium] & 18 & 136 & $60.3 \pm 6.7$ & 0.3403 \\
\hline Hoxa1-endo[high] & 6 & 84 & $24.6 \pm 10.9$ & $<0.0001$ \\
\hline Math1-endo[low] & 15 & 157 & $59.6 \pm 6.8$ & 0.3515 \\
\hline Math1-endo[medium] & 7 & 86 & $35.0 \pm 10.7$ & 0.0032 \\
\hline Math1-endo[high] & 8 & $6.3 \pm 6.5$ & $<0001$ \\
\hline
\end{tabular}

Concomitant expression of Endoglycan could rescue the aberrant axon guidance phenotype induced by the downregulation of Endoglycan throughout the spinal cord. It did not matter whether Endoglycan was expressed under the Hoxa1 promoter for specific expression in floor-plate cells, or under the Math1 promoter for specific expression in dI1 neurons. However, the rescue effect was dose-dependent. Too little, or too much Endoglycan was inducing axon guidance defects. The rescue constructs, Endoglycan cDNA under control of the Hoxa1 promoter (Hoxa1-endo) and the Math1 promoter (Math1-endo) were injected at $150 \mathrm{ng} / \mu \mathrm{l}$ (low), 300 $\mathrm{ng} / \mu \mathrm{l}$ (medium), or $750 \mathrm{ng} / \mu \mathrm{l}$ (high). The number of embryos and the number of Dil injection sites analyzed per group are indicated. The average $\%$ of injection sites with normal axon guidance phenotypes and the $\mathrm{P}$-value for the comparison between the respective group and the control-treated (EGFP-expressing) group are given. 
Table 2

Endoglycan decreases lengths of motor axons

\begin{tabular}{|c|c|c|}
\hline Experimental condition & Average neurite length & Number of axons \\
\hline COS-BFP/MN-GFP & $88.4 \pm 4.0 \mu \mathrm{m}$ & 334 \\
\hline COS-BFP/MN-Endo & $59.1 \pm 2.6 \mu \mathrm{m}$ & 342 \\
\hline COS-Endo/MN-GFP & $80.4 \pm 2.7 \mu \mathrm{m}$ & 288 \\
\hline COS-Endo/MN-Endo & $50.3 \pm 2.4 \mu \mathrm{m}$ & \\
\hline
\end{tabular}

Motor axons expressing ectopic Endoglycan (MN-Endo) were shorter than control-treated motor axons expressing GFP (MN-GFP). This effect was stronger when the COS cells used as carpet were also expressing Endoglycan (COS-Endo) compared to blue-fluorescent protein (COS-BFP). 